\title{
Characterization of noise and design of active noise control technology in longwall mines
}

Arunkumar R. Rai

West Virginia University

Follow this and additional works at: https://researchrepository.wvu.edu/etd

\section{Recommended Citation}

Rai, Arunkumar R., "Characterization of noise and design of active noise control technology in longwall mines" (2005). Graduate Theses, Dissertations, and Problem Reports. 4187.

https://researchrepository.wvu.edu/etd/4187

This Thesis is protected by copyright and/or related rights. It has been brought to you by the The Research Repository @ WVU with permission from the rights-holder(s). You are free to use this Thesis in any way that is permitted by the copyright and related rights legislation that applies to your use. For other uses you must obtain permission from the rights-holder(s) directly, unless additional rights are indicated by a Creative Commons license in the record and/ or on the work itself. This Thesis has been accepted for inclusion in WVU Graduate Theses, Dissertations, and Problem Reports collection by an authorized administrator of The Research Repository @ WVU. For more information, please contact researchrepository@mail.wvu.edu. 


\title{
CHARACTERIZATION OF NOISE AND DESIGN OF ACTIVE NOISE CONTROL TECHNOLOGY IN LONGWALL MINES
}

\author{
Arunkumar R. Rai
}

Thesis submitted to the College of Engineering and Mineral Resources at West Virginia University in partial fulfillment of the requirements for the degree of

\author{
Master of Science \\ in \\ Mining Engineering
}

\author{
Approved by \\ Yi Luo, Ph.D., Chair \\ Syd S. Peng, Ph.D, \\ Felicia F. Peng., Ph.D
}

Department of Mining Engineering

Morgantown, West Virginia

2005

Keywords: Noise, Longwall mining, Noise survey, Active noise control. 


\title{
ABSTRACT \\ CHARACTERIZATION OF NOISE AND DESIGN OF ACTIVE NOISE CONTROL TECHNOLOGY IN LONGWALL MINES
}

\author{
by
}

\section{Arunkumar R Rai}

Production and safety have always been a prime issue for mining industry and mining engineers, who strive hard to achieve the critical balance between them. Hearing loss and uneasy working environment are few common ones affecting the health statistics of a underground mine. As a result, recent years there have been the focus on to develop an engineering controls to reduce the underground noise. Unique work has been done in this thesis to add additional information on the active noise control technology applied to Longwall mining operations.

The frequency distribution patterns of the maximum and the minimum SPL and the Octave Band Analysis (OBA) revealed very complex and multidirectional relationship between the free fields, near field locations in the openings. The change in the average SPL with the change in the location of measurement and frequency distribution resembled a unique distribution curve. However, the effect of the frequency distribution, Overall SPL and location of measurement lacked clear trend for the different input combinations considered. Thus it was difficult to predict any particular trend for the sound pattern in and around the longwall face.

Experiments are performed under laboratory conditions to accomplish the application of the theory. Active noise control software, Oros analyzer and various Quest's instruments has been used to examine the spectrum of various underground noise sources. Distribution patterns of frequencies spectrum were used to explain the overall contribution towards noise in the entry or the face. Also, the FFT was used to analyze the pattern. In order to widen the area of work, both active and passive controls have been discussed.

Mostly, the survey results indicated that the frequency content of each noise and the number of events decide on the effect on worker. Also, in Stage loader the Lower frequencies showed a significant contribution to the overall sound pressure level (SPL). However, under some combinations the contribution of higher frequencies cannot be denied. Based on these findings, Active Noise Control (ANC) set-up was prepared for canceling the unwanted frequencies and reduces the overall sound pressure level. It was also found that the ANC was more effective for the lower frequencies ranging from $100 \mathrm{~Hz}$ to $700 \mathrm{~Hz}$ and cancellations were more significant for the low frequencies than for the higher ones. 
To

My Parents and Teachers 


\section{ACKNOWLEDGEMENTS}

With all respect and gratitude, I would like to express my sincere thanks to all members of my advisory and examination committee for their advices and comments.

I am deeply indebted to Dr. Syd Peng and Dr. Felicia Peng for serving on my Master theses Committee. Sincere gratitude and appreciation to my research advisor and the Committee Chair Dr. Yi Luo, for his encouragement and guidance during my stay in WVU. I will always cherish the share of knowledge, I acquired from Dr.Syd Peng's research group. On a more personal note, I am privileged and honored to be a part of this research group. The multi-varied discussions and presentations by group researchers under your supervision were inspiring. Also, I appreciate my theses committee member's suggestions and invaluable help for structuring my work. This work was performed under a project sponsored by CDC/NIOSH "Developing Engineering control for noise control in mines". Their financial support is gratefully acknowledged.

Also, Special thanks to Dan Alexander for his interest and assistance in my research work. I acknowledge invaluable help by noise group at PRL, NIOSH. I wish to thank all coal mine personnel's for their cooperation. I also appreciate the help received from the Mining Engineering Department, WVU and Jeremy Slagley, Department of Industrial Engineering for his discussions.

Personally, I am deeply indebted to my parents for their love, support, encouragement at all times. I am thankful to my brother and sister for their encouragement and support.

Finally, I express my sincere appreciation to all those who directly or indirectly contributed to the preparation and completion of the thesis. 


\section{TABLE OF CONTENTS}

ABSTRACT

\section{CHAPTER 1}

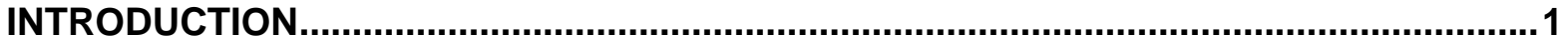

\section{CHAPTER 2}

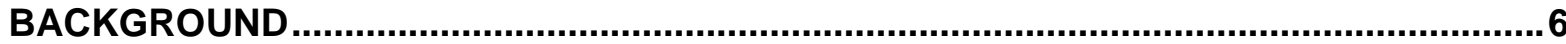

2.1 Noise Characterization and Noise Cancellation Technology ...................... 8

\section{CHAPTER 3}

NOISE SURVEY AND CHARACTERIZATION OF NOISE FIELDS ...............................18

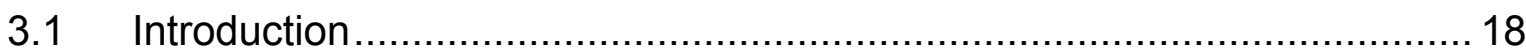

3.2 Noise in Underground Coal Mining:................................................ 20

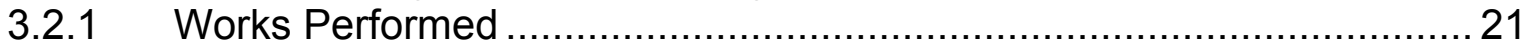

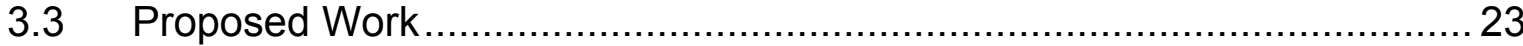

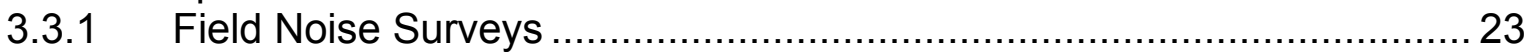

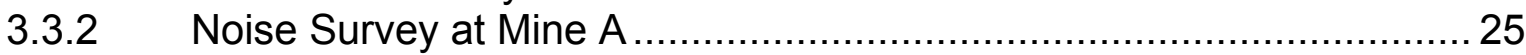

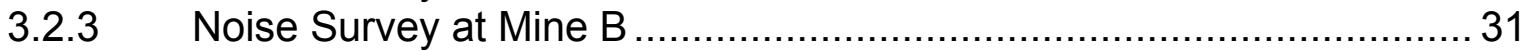

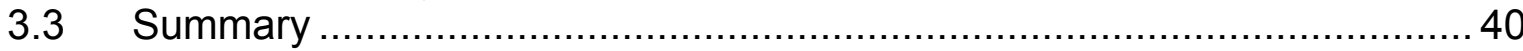

\section{CHAPTER 4}

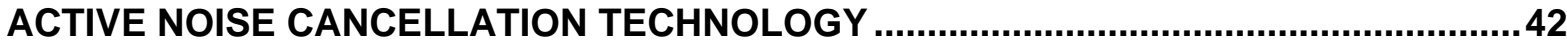

4.1 Active Noise and Passive Noise Control Technology ............................42

4.2 Laboratory Noise Survey ................................................................. 43

\section{CHAPTER 5}

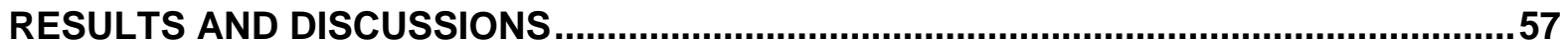

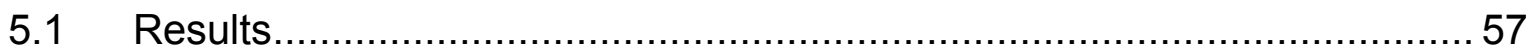

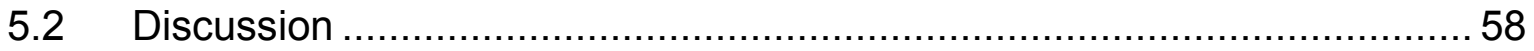

CHAPTER 6

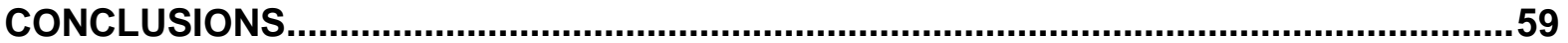

CHAPTER 7

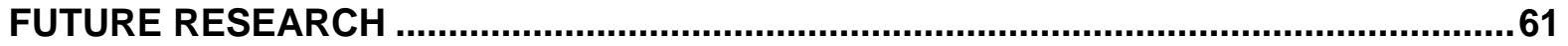

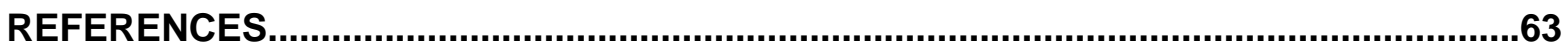




\section{LIST OF TABLES}

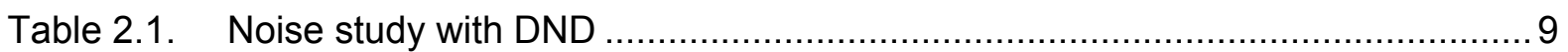

Table 2.2. NIHL cases by mine area $\quad$.................................................................... 11

Table 3.1. Dose contribution and SPL by activities for tailgate shearer operator............. 29

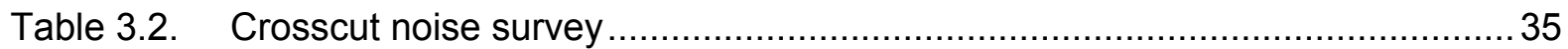

Table 3.3. Octave band analysis at the stage loader ............................................... 37

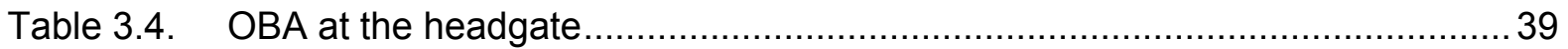

Table 4.1. Testing Parameters and noise reduction ..................................................50 


\section{LIST OF FIGURES}

Figure 1.1 Hearing impairment in coal miners, non-coal miners and non exposed males

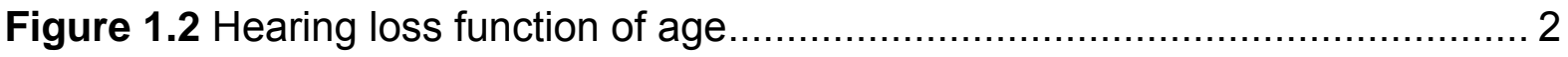

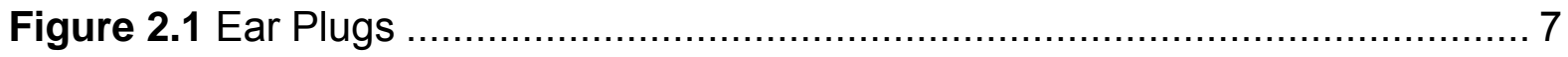

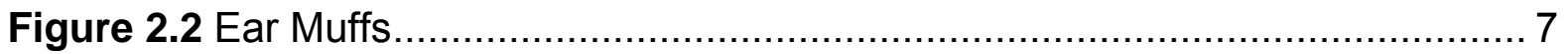

Figure 2.3 Kemar Manikin ANCHP attenuation for ANC turned on and off without safety glasses in pure tone, reverberant sound fields .......................... 9

Figure 2.4 Kemar Manikin ANCHP attenuation for ANC turned on and off with safety glasses in pure tone, reverberant sound fields .................................. 10

Figure 2.5 Longwall face Sound Levels (dBA) …........................................ 13

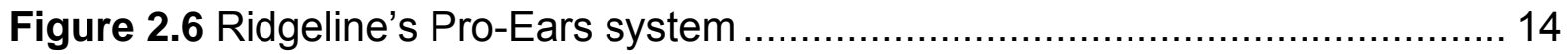

Figure 2.7 Cumulative dose plot for roof bolter operator .................................. 15

Figure 2.8 Cumulative dose plot for cell operator............................................. 15

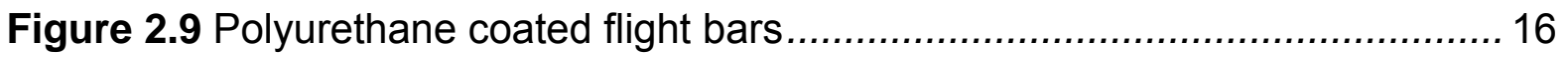

Figure 3.1 Typical longwall retreating panel layout ......................................... 20

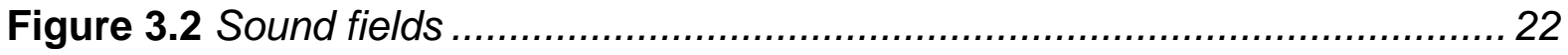

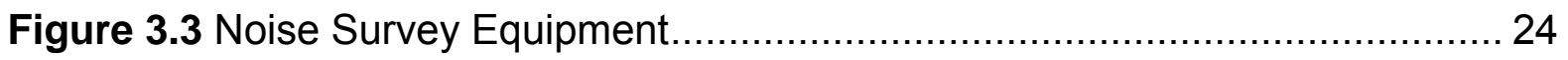

Figure 3.4 Noise Level at Different section of a Stage Loader ............................ 26

Figure 3.5 Noise exposure dose for headgate operator at the stage loader .......... 27

Figure 3.6 Noise exposure dose for tailgate shearer operator ............................ 28 
Figure 3.7 Results of octave analysis of the noise field along the stage loader ...... 30

Figure 3.8. Overall SPL aligned with Length of the Stage Loader......................... 32

Figure 3.9 SPL along the Stage Loader Section ............................................. 33

Figure 3.10 Overall SPL aligned with Length of the Stage Loader........................ 34

Figure 3.11 SPL at the Longwall Face with respect to Shield Number.................. 36

Figure 3.12. OBA along the Stage Loader at Mine B ..................................... 38

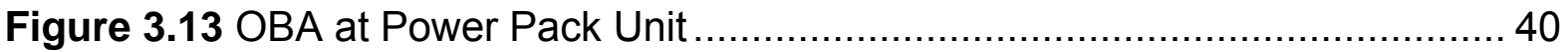

Figure 4.1 Schematic of feed forward active noise control system in a duct ........... 43

Figure 4.2 The laboratory setup for ANC experiment.................................... 44

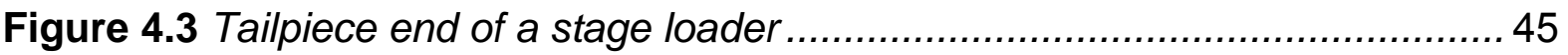

Figure 4.4 Equipments used in ANC laboratory experiments............................ 46

Figure 4.5 Manual Input screen for EZ-ANZ II controller ................................... 48

Figure 4.6 Result screen capture of the OROS octave band analyzer ...................50

Figure 4.7 Measured on segment A of the recorded stage loader noise ................5 51

Figure 4.8 Measured sound pressure levels vs. frequency for various tests on noise

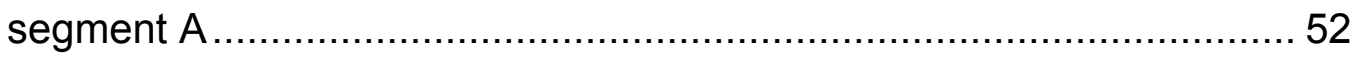

Figure 4.9 Reductions on sound pressure levels at different frequency sampled at

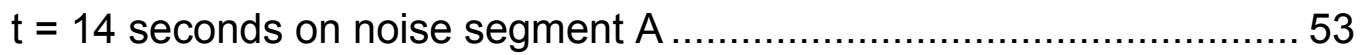

Figure 4.10 Reductions on segment B of the recorded stage loader noise ............ 54

Figure 4.11 Measured sound pressure levels and reduction for test T16 on noise

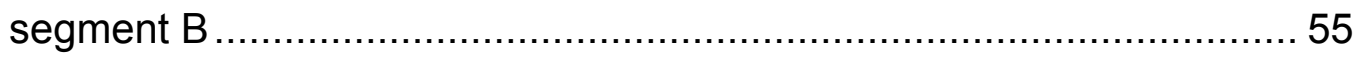


Figure 4.12 Tests performed on all 14 noise segments with the control parameters

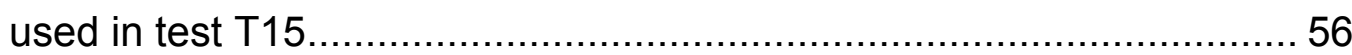




\section{GLOSSARY}

Where possible, the definition is quoted from the appropriate American National Standards Institute (ANSI) standard, ANSI S1.1-1994 [ANSI 1994] or ANSI S3.201995 [ANSI 1995], under the term(s) used in that standard.

Audiogram: Graph of hearing threshold level as a function of frequency (ANSI S3.20-1995: audiogram).

Continuous noise: Noise with negligibly small fluctuations of level within the period of observation (ANSI S3.20-1995: stationary noise; steady noise).

$$
D=\left[C_{1} / T_{1}+C_{2} / T_{2}+\ldots+C_{n} / T_{n}\right] H 100
$$

- $\mathrm{C}_{\mathrm{n}}=$ total time of exposure at a specified noise level $T_{n}=$ exposure time at which noise for this level becomes hazardous

Decibel ( $d B)$ : Unit of level when the base of the logarithm is the 10th root of 10 and the quantities concerned are proportional to power (ANSI S1.1-1994: decibel).

Decibel, A-weighted (dBA): Unit representing the sound level measured with the Aweighting network on a sound level meter. (Refer to Table 4-1 for the characteristics of the weighting networks.)

Decibel, $C$-weighted $(d B C)$ : Unit representing the sound level measured with the Cweighting network on a sound level meter. (Refer to Table 4-1 for the characteristics of the weighting networks.)

DND: Daily Noise Dosage

Dose: The amount of actual exposure relative to the amount of allowable exposure, and for which $100 \%$ and above represents exposures that are hazardous. The noise dose is calculated according to the following formula:

Excess risk: Percentage with material impairment of hearing in an occupationalnoise-exposed population after subtracting the percentage who would normally incur such impairment from other causes in a population not exposed to occupational noise.

Exchange rate: An increment of decibels that requires the halving of exposure time, or a decrement of decibels that requires the doubling of exposure time. For example, a 3-dB exchange rate requires that noise exposure time be halved for each 3-dB increase in noise level; likewise, a 5-dB exchange rate requires that exposure time be halved for each $5-\mathrm{dB}$ increase. 
Frequency: For a function periodic in time, the reciprocal of the period. Unit, hertz (Hz) (ANSI S1.1-1994: frequency).

MSHA: Mine Safety and Health administration.

NIHL: Noise Induced Hearing Loss.

NIOSH: National Institute for Occupational Safety and Health.

Noise reduction rating (NRR): The NRR, which indicates hearing protector's noise reduction capabilities, is a single-number rating that is required by law to be shown on the label of each hearing protector sold in the United States. Unit, dB.

Noise: (1) Undesired sound. By extension, noise is any unwarranted disturbance within a useful frequency band, such as undesired electric waves in a transmission channel or device. (2) Erratic, intermittent, or statistically random oscillation (ANSI S1.1-1994: noise).

Sound pressure level: (1) Ten times the logarithm to the base ten of the ratio of the time-mean-square pressure of a sound, in a stated frequency band, to the square of the reference sound pressure in gases of 20 micropascals $(\mu \mathrm{Pa})$. Unit, dB; symbol, $L_{p}$. (2) For sound in media other than gases, unless otherwise specified, reference sound pressure in $1 \mu \mathrm{Pa}$ (ANSI S1.1-1994: sound pressure level).

Sound pressure: Root-mean-square instantaneous sound pressure at a point during a given time interval. Unit, Pascal (Pa) (ANSI S1.1-1994: sound pressure; effective sound pressure).

Sound: (1) Oscillation in pressure, stress, particle displacement, particle velocity, etc. in a medium with internal forces (e.g., elastic or viscous), or the superposition of such propagated oscillations. (2) Auditory sensation evoked by the oscillation described above (ANSI S1.1-1994: sound).

Time-weighted average (TWA): The averaging of different exposure levels during an exposure period. For noise, given an 85-dBA exposure limit and a 3-dB exchange rate, the TWA is calculated according to the following formula:

$$
\text { TWA }=10.0 \mathrm{H} \log (\mathrm{D} / 100)+85
$$

Where $\mathrm{D}=$ dose . 


\section{CHAPTER}

\section{1 introouction}

The two most important pillars for mining industry are Safety and Production. As per rule of thumb, the safest mine is the highest producing mine. New health and safety standards will be adopted and enforced by the government agencies. Underground mining is more challenging and excavation depends on the machinery and human workforce who are employed. Some of the major issues are dust exposure, roof control and noise exposure. The research highlights over the past few years indicate a strong program for addressing the issue of hearing loss due to unwanted sound .i.e. "NOISE". Good hearing helps an individual to have better quality life in the society. Occupational noise may cause irreversible hearing damage after prolonged exposure to high noise levels. For example, a NIOSH (1996) study shows that $10 \%$ of coal miners suffer hearing loss by age 30 (NIOSH, 1996). This is equivalent to the rate for the non-occupationally exposed population by age 51 . By age $50,90 \%$ of coal miners have developed hearing impairment. By contrast, only $10 \%$ of the nonoccupational noise-exposed population had a impairment by age 51 . Among the working places in underground mines, the longwall mining faces could be noisier than other locations due to the use of heavy and energy-intensive equipments in the rock breakage (cutting and crushing) and haulage operations in a confined working space.

A noise study in 1996 and 1997 by NIOSH presented a plot shown in Fig 1.1 expressed an average hearing loss greater than $25 \mathrm{~dB}$ for coal miners and non-coal miners compared to that of non exposed males. Noise induced hearing loss (NIHL) is a major health issue in the mining industry because the average age of the present workforce is 50 year old and above. Fig. 1.2 shows that hearing loss is surely a function of age. Workers with age 50 and more have a hearing loss greater than $25 \mathrm{~dB}$. 


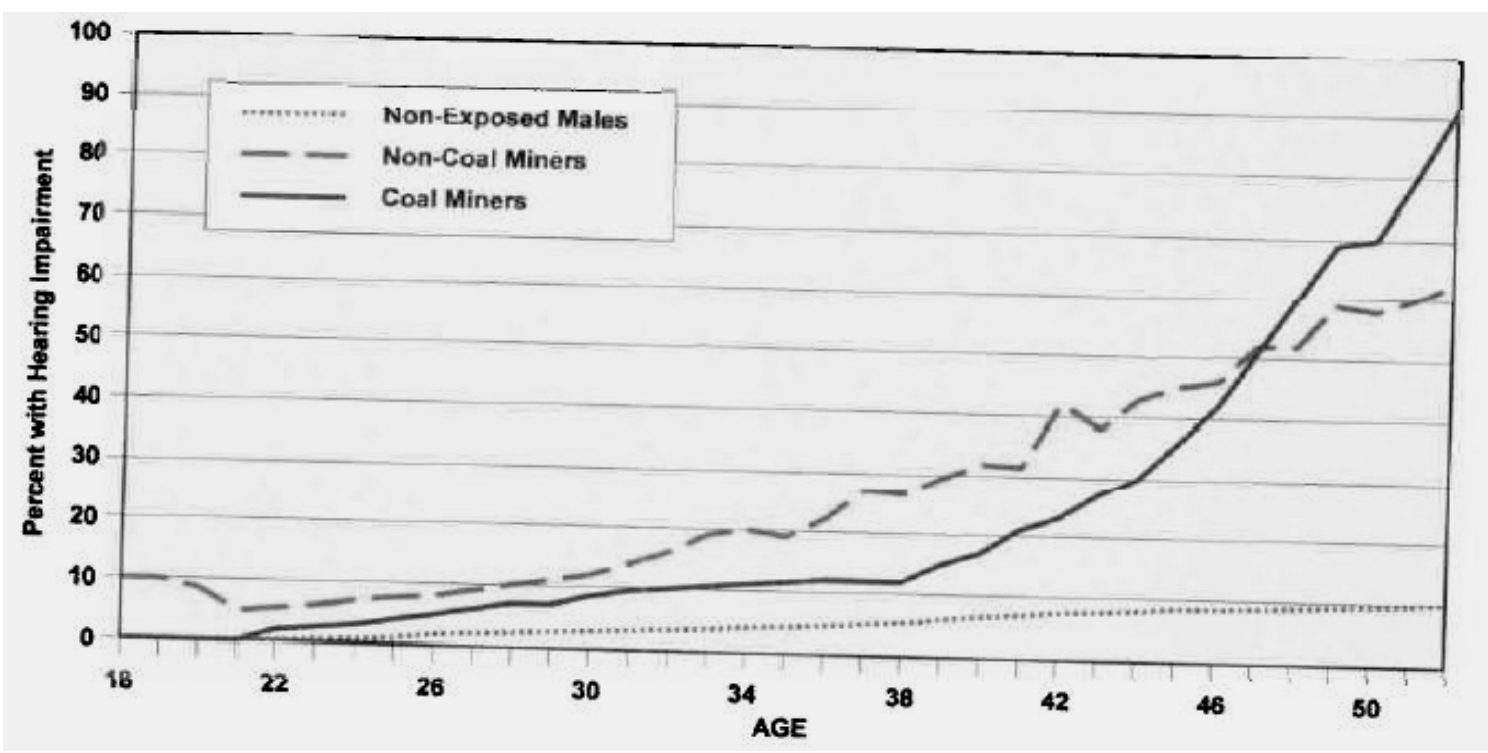

Figure 1.1 Hearing impairment in coal miners, non-coal miners and non exposed males (NIOSH 1996b, 1997).

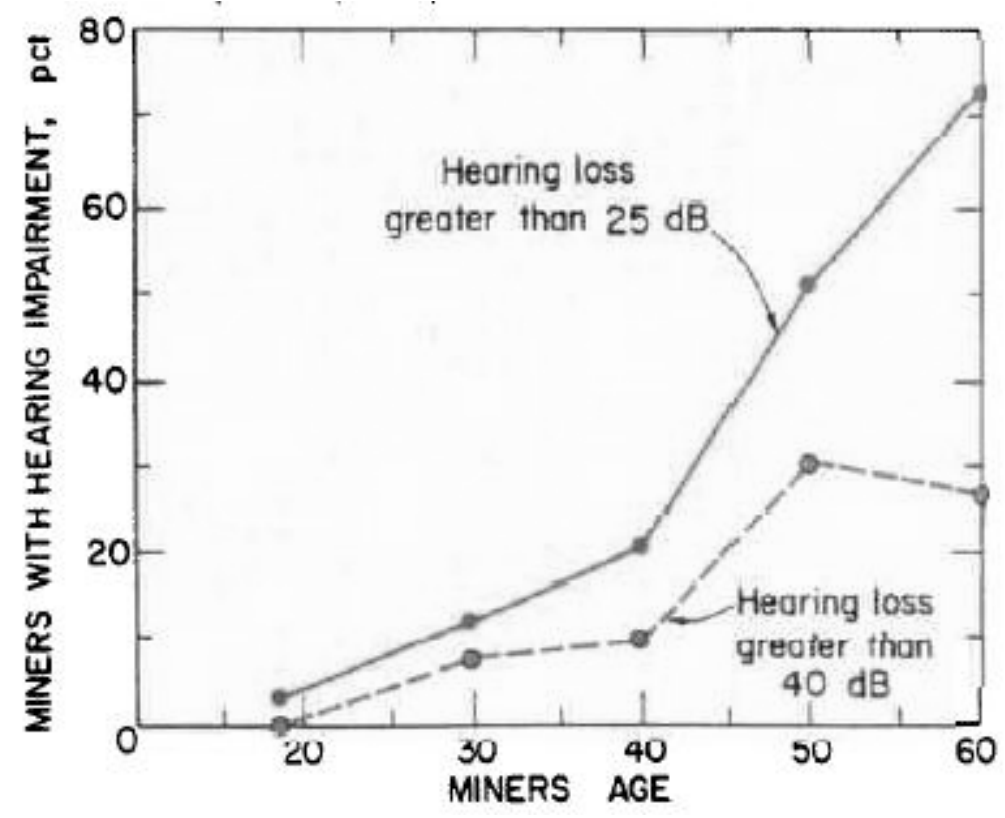

Figure 1.2 Hearing loss function of age (NIOSH, 1976).

Longwall mining should enjoy a long and secure future with the present trend. Most of the longwall mining operations in the Pittsburg seam have 6-8 $\mathrm{ft}$ thick coal seam. Generally they have two mile long, 1300 foot wide longwall panel. Shearer, face conveyor and stage loader are the most important production units and consume high power for their operation. e.g. A Joy $7 \mathrm{LS} 2$ shearer incorporates $545 \mathrm{hp}$ ranging arms, DBT face conveyor is driven by a $350 \mathrm{hp}$ motor. Similarly stage loader 
also need high electric power supply to operate its crusher and other units. Also, in future by using intelligent cutting sequence it is possible that shearer loader productivity can be increased by up to $50 \%$ (Nienhaus, et al., 2005). The reason to mention these machines is to draw a picture of a highly mechanized longwall face with installation of high power consuming machines, which in turn produces a high noise through its operation. These noisy machine operations are developing a health concern among the miners and mine operators. Thus, it can be easily understood that noise exposure is directly proportional to equipment size with high horsepower.

In order to design and implement effective engineering noise controls, the characteristics of the noise sources and noise fields should be understood. The current research considers the effect of both low and high frequency on the overall sound pressure level in coal mine workings. Additionally, more detailed frequency analysis will be made at different points in the face by octave band analysis (OBA) and sound pressure level (SPL) measurement, which reflects the combined effect of the frequencies. The important aims of this work are evaluation of the active noise cancellation technique and apply it where appropriate engineering controls are targeted to reduce excessive noise exposures to workers.

Introduction of faster computer and tremendous advances in the signal processing techniques, it is now possible to incorporate complex random noise signals in any conditions and perform an analysis. The main factors responsible for most of the overall noise are mine types, equipments used, mining method and geographic location. Representative overall sound pressure level noise profile for various equipments show frequency as a dominant factor. Engineering control for reducing noise provides a systematic solution. Other Industries have already incorporated Active noise cancellation (ANC) technique and some excellent works are available on this issue, but yet mining industry needs more research to be done before a comprehensive understanding of the noise cancellation is developed. This thesis work is an effort to develop the possible application of ANC in mining industry. 
The problem of noise Induced hearing loss has existed since the Middle Ages; In the professions like blacksmithing seems to have begun as early as 1831 and known to be as "blacksmith's deafness" (Bauer and Babich, 2004). In World War II, a large number of soldiers returned home with lost hearing. Thus one of the earliest regulations for hearing conservation was Air Force Regulation 160-3, issued in 1948 (DOAF, 1948). Now, with the advances in the noise measuring techniques that confirm the existence of low and high frequency noise, the sound pressure level in a majority of cases is ascribed to the high frequency noise. This can be witnessed by the deluge of publications on this subject. However, a complete study on the SPL related NIHL should consider both the high and the low frequency noise as the Octave Band Analysis (OBA) in the mines also show the existence of low frequency noise.

Thus equal importance is given to both low and high frequency in this research. Further, the cancellation effects are also investigated for the lower frequency. The combination of active and passive control for low and high frequency respectively could control noise related problems and help the miners to lead a better life. Various studies in the past proved that providing good hearing condition improved on-the-job communication which resulted in high production, lower losstime accidents and workers maintain good health.

The parameters accountable for overall SPL in an underground mine situation are too many to unite in a research of this level. To make the research easy to handle, limitations have been established on the number of variables and their greatness in significance considered in this thesis. To make the results more practical and meaningful, real time actual mine noise condition are developed and the magnitude of the variables similar to underground mining condition are created in the laboratory designs. This research is an earnest attempt to achieve the following specific objectives:

- To study the characteristics of noise field in and around the longwall faces. 
- Evaluate the NIHL effects of both low and high frequency noise in underground mining environments.

- Justify logical reason for the need to cancel low frequency noise.

- Enhancing knowledge on the effect of low frequency noise on the overall SPL at the Longwall working faces.

- To develop proper engineering noise control measures and to evaluate their effectiveness for Longwall underground coal mines. 


\section{BACKGROUND}

Extensive work on NIHL have been done in the 1970s and 80s. Some of these constitute a broad range of mining conditions. Since the present research is focused at engineering noise control techniques in underground coal mines, only important works related to this topic are reported.

The number of factors governing the noise level in underground mining environment is too many to cover all of them. The complex interaction of all these parameters makes it difficult for any analytical methods to accurately estimate noise pattern state at a point in the mining face. Hence, often the only choice available is to measure the SPL in the field. Thus noise surveys are done in the mines with proper intrinsically safe noise measuring and recording devices (Armour, 2003; Bauer and Babich, 2004; Peterson, et al., 2005).

The mining industry in United States has adopted a number of noise measurements techniques as described by Armour (2003), Bartholomae (1983) International standard ISO, (1990) and MSHA 30 CFR. These field surveys conducted indicate that the overall SPL in the coal mines is combined effect of low and high frequency noise. The purpose of these field surveys is to characterize the mine noise and acoustic energy distribution in the possible range for proper selection of noise control measure.

The frequency spectrum analysis provides the knowledge about the influence of low and high frequency noise, particularly, the existence and the effect of low frequency noise on NIHL in the coal mining industry. Many researchers worked on the problem of noise control and offered explanations based on field and analytical work. In general most of the work was concentrated on administrative noise 
controls. Low frequency control technology related problems were also reported. Bies and Hansen (2003). In United States various experiments were completed to develop engineering noise control technology.

The most common noise and engineering controls in others industries include hearing protection devices (HPD) such as ear plugs, ear muffs etc. These HPD are highly dependent on the user interest, motivation and skills. Thus the effectiveness of HPD is very unpredictable for different users. Fig. 2.1 shows ear plugs which are commonly used and easily available everywhere. Fig. 2.2 shows a type of ear muffs used as HPD.
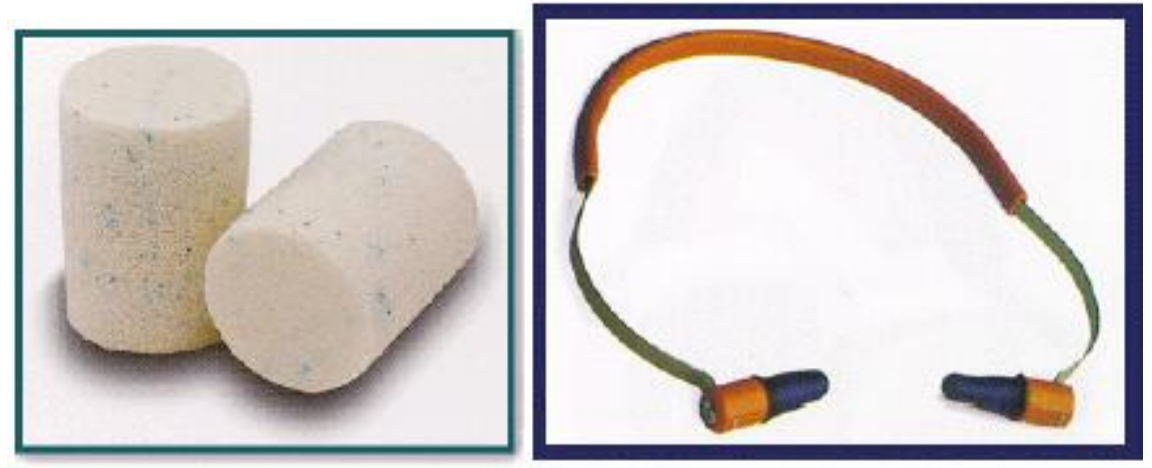

Figure 2.1 Ear Plugs

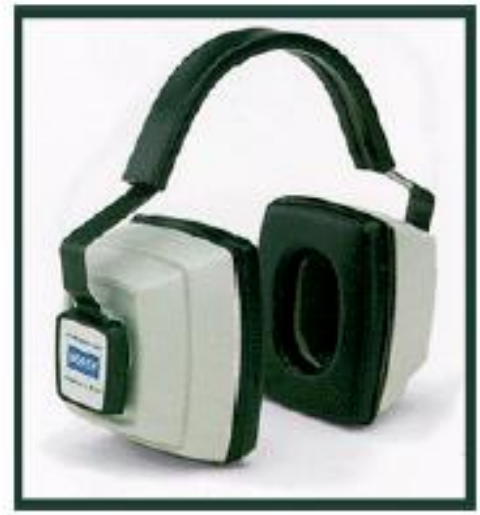

Figure 2.2 Ear Muffs 


\subsection{Noise Characterization and Noise Cancellation Technology}

The engineering control of mine noise through active noise cancellation is a new area for the mining industry compared to other industries. The technology uses the theory of arbitrary mixing of the source noise and anti-noise waves resulting in a sound field with reduced sound pressure level. The principle is patented by Leug in (1934). The possible success of the theory was achieved in other industries like aviation; submarines etc prompted the researchers to explore the possibility of its application in the more complicated longwall mining industry. Although very few researcher were noticed working on the noise cancellation technology in mining. Most of them had experienced similar problem of canceling frequencies above 500 $\mathrm{Hz}$.

In 1983, the former U.S. Bureau of Mines developed a handbook entitle, "Mining Machinery Noise Control Guidelines, 1983", which was documented by Bartholomae (1996). The author studied a noise control on various pieces of mining equipment for dissemination to the mining industry. Bartholomae and Burks proposed several noise treatments methods for different machines in underground mining conditions, and a data analysis on the longwall face for noise exposure to workers (1996). These authors correlated noise table for shield setters, shearer operator and headgate operator. The average daily noise dosage (DND) represented in six longwall mines using MSHA DND regulation (90/90/5) are shown in table 2.1. Here they used criterion level as 90 , threshold limit was set as 90 with 5 as the exchange rate. 
Table 2.1 Noise Study with DND (Bartholomae, 1996).

\begin{tabular}{|l|c|}
\hline \multicolumn{1}{|c|}{ Occupation Title } & MSHA DND ( 90/90/5 ) \\
\hline 1. Shearer Headgate & 129 \\
\hline 2. Shearer Tailgate & 126 \\
\hline 3. Shield Setter two workers & 47 \\
\hline 4. Headgate Operator & $\mathbf{7 0}$ \\
\hline
\end{tabular}

Back in 1996, Bartholomae concluded that engineering noise controls be used at longwall face to reduce workers noise exposure. He also pointed out the case of headgate operator to be treated with proper administrative and/or engineering controls. His work on active noise cancellation performance in hearing protectors showed some positive results for pure tone frequencies. The figure 2.3 shows the repeated procedures of ANC for pure tones at 250,500, 1000 and 4000 $\mathrm{Hz}$. The results plotted are curves for ANC 'on' and ANC 'off' for the earmuff. Also, a test results for the ANC when safety glasses were placed on the manikin with the set-up are shown in Fig 2.4.

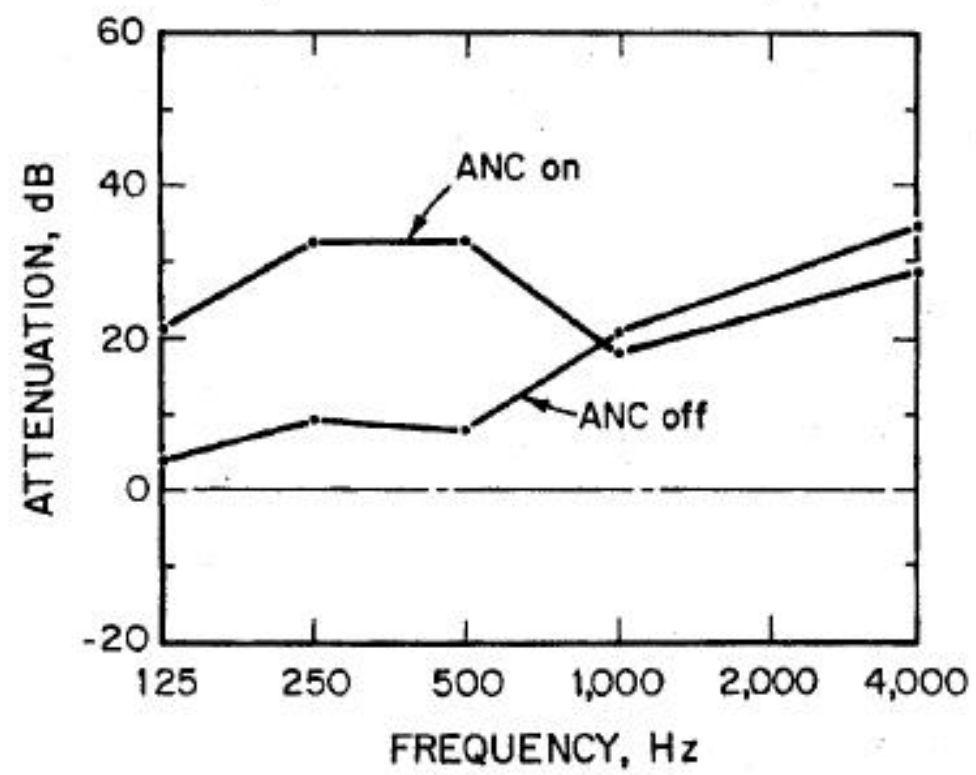

Figure. 2.3 Kemar Manikin ANCHP attenuation for ANC turned on and off without safety glasses in pure tone, reverberant sound fields. (Bartholomae and Burks, 1996) 


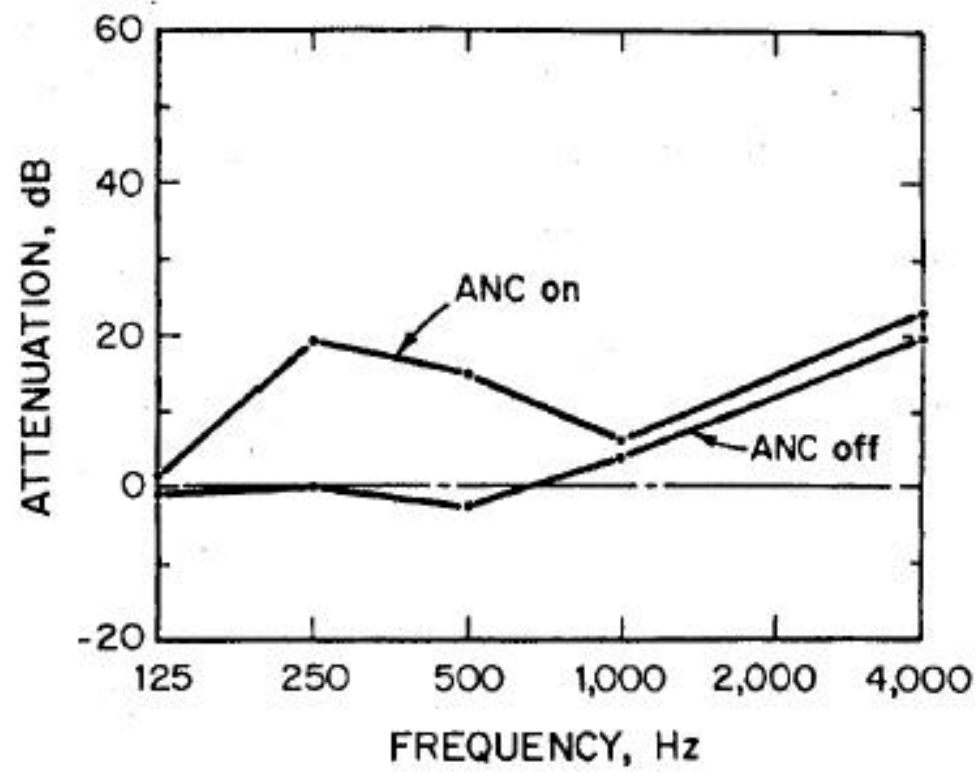

Figure 2.4 Kemar Manikin ANCHP attenuation for ANC turned on and off with safety glasses in pure tone, reverberant sound fields. (Bartholomae and Burks, 1996)

Although their work explained some broad features of noise exposure and active noise control experiments, it was very rudimentary in its approach. The ANC experiments were done on pure tones conditions which showed some success but the random noise results are not clear from the analysis.

Valoski's (1997) investigated the noise exposure in mining industry and revealed a good picture for different areas of noise exposure. His research contains statistical analysis based on the data provided by mine operators reporting instances of NIHL. The results presented the temporal distribution of NIHL cases and the occupation and age of miners who incurred NIHL. 
Table 2.2 NIHL cases by mine area (Valoski, 1997)

\begin{tabular}{|c|l|c|}
\hline Serial. no. & Area of the Mine & Number of NIHL Cases \\
\hline 1 & Surface area of underground mine & 24 \\
\hline 2 & Underground Mine & 454 \\
\hline 3 & Strip Mine & 53 \\
\hline 4 & Preparation Facility & 105 \\
\hline 5 & Independent Shop & 26 \\
\hline 6 & Office & 2 \\
\hline 7 & Not Reported & 1 \\
\hline
\end{tabular}

Table 2.2 justifies the assumption that underground mining places are more noisy compare to other areas of the mine. The various reasons may include the confined area, number of people within a limited time and use of high horsepower machinery etc.

Valoski (1993) also studied on the technical feasibility of noise cancellation technology (NCT). He used NCT2000 in his experiments which were conducted under laboratory conditions. The internal switches were set to cancel the highest frequency of which it was capable. The NCT 2000 theoretically has an upper frequency limit $3000 \mathrm{~Hz}$. The noises were pure tones at the third octave band center frequencies between 80 to $1000 \mathrm{~Hz}$. Although this work explained some broad field observations, it was very rudimentary in its approach. The beam theory equations used in the paper did not clearly explain the conditions reported for different orientations.

In 1996, Frank collaborated work for $\mathrm{NIOSH}$ and MSHA that was designed to determine the prevalence of hearing loss among miners (ISO, 1990; NIOSH, 1996). The report contained an analysis of 17260 audiograms for 2871 coal miners. ISO 1999 was followed to calculate and predict the amount of hearing loss observed for 
the miners. The author showed that, by the time coal miner reaches the age of 50 , $50 \%$ of them have hearing impairment. Thus NIHL is considered to be a major set back for mining health standard and high production goals.

Armour (2003) researched for the better hearing loss prevention program and to understand the source of noise underground did a noise study. The author summarized the sources responsible for the longwall noise and also examined the technical controls at a mine. Using cycle events and area event, Armour inferred that there are three primary sources of noise: the chain, the drives, and the crusher. The cutting was major cause for the shearing machine noise. Armour also listed heat and maintenance as important factors to be considered. This work used dosimeter to get full shift time study. He used dosimeter event method and recorded separate events on a single dosimeter. He suggested two types of events recording: a cycle event and an area event.

Fig. 2.5 shows detail SPL measurements taken from more than 30 longwall faces using the dosimeter event method. Fig. 2.6 shows helmet which is Ridgeline's Pro-Ears system suppresses all noise above $85 \mathrm{dBA}$ while simultaneously amplifying lower sounds, such as human conversation. 


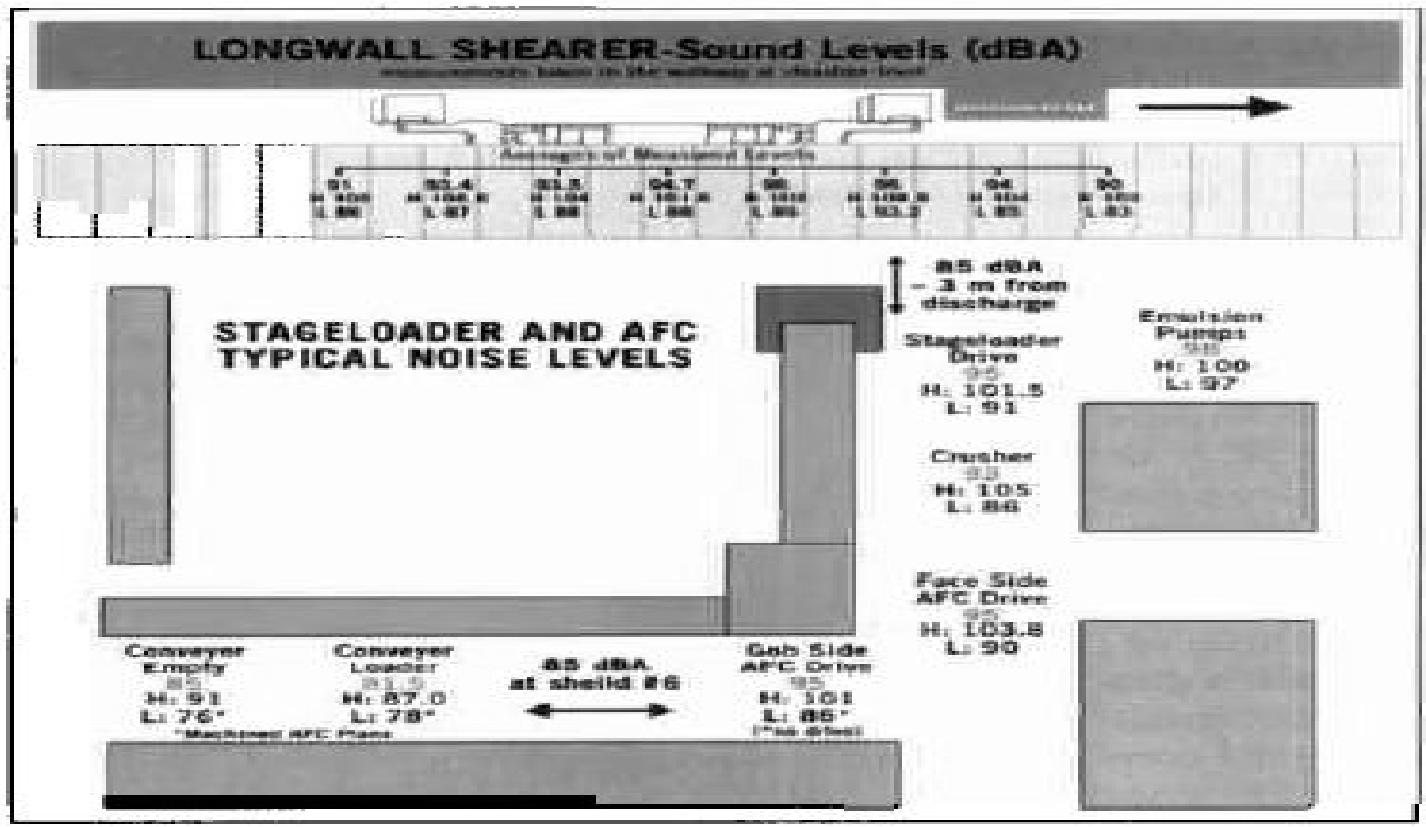

Average measured sound levels measurements were taken on more than 30 longwall faces using the dosimeter event method. The environmentai nolse levels are shown on the diagrams.

Figure. 2.5 Longwall face Sound Levels (dBA). (Armour, 2003)

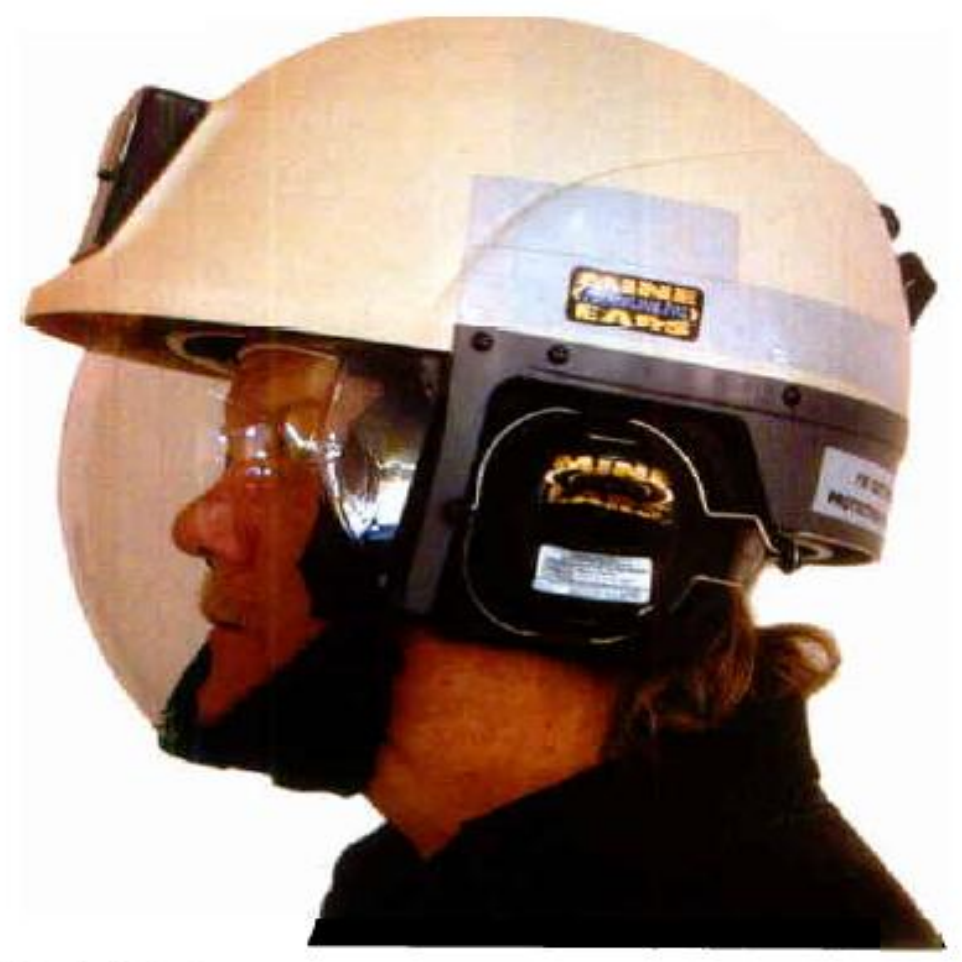

Ridgeline's Pro-Ears system suppresses all noise above $85 \mathrm{dBA}$ while simuttaneously amplifying lower sounds, such as human conversation.

Figure. 2.6 Ridgeline's Pro-Ears system (Armour, 2003). 
Chiang, et al., (1987) determined airborne dust distribution in Longwall mines and included dust survey for underground mines. The reason to mention this work is for its methodology. They have used some good ideas of surveying with concern with different part in longwall face. Peng and Chiang (1984) also have plotted a good and clear picture longwall mining method and the layout of Longwall mining face. Attempt is made to get some of the surveying ideas from their work and make much better representation of noise survey.

Bauer and Babich (2004) provided a study for what constitutes administrative controls for reducing workers noise exposure and also a qualitative explanation of the process of implementation and evaluation of an administrative control. He also summarized the main factors responsible for the noise exposure and they were: the type of task, workers location, noise concentration, SPL characteristics, and duration of exposure. They conducted a study on various equipments used in the mines. They suggested that administrative controls should be based on the periods of exposure that results in largest dose. Fig. 2.7 and Fig. 2.8 shows an example of cumulative dose plot for roof bolter operator and cell operator.

On the observation of his studies in the longwall mining sections, Bauer concluded that job switching/rotation, workers locations and equipment Operation can be the prime areas for effective administrative control. 


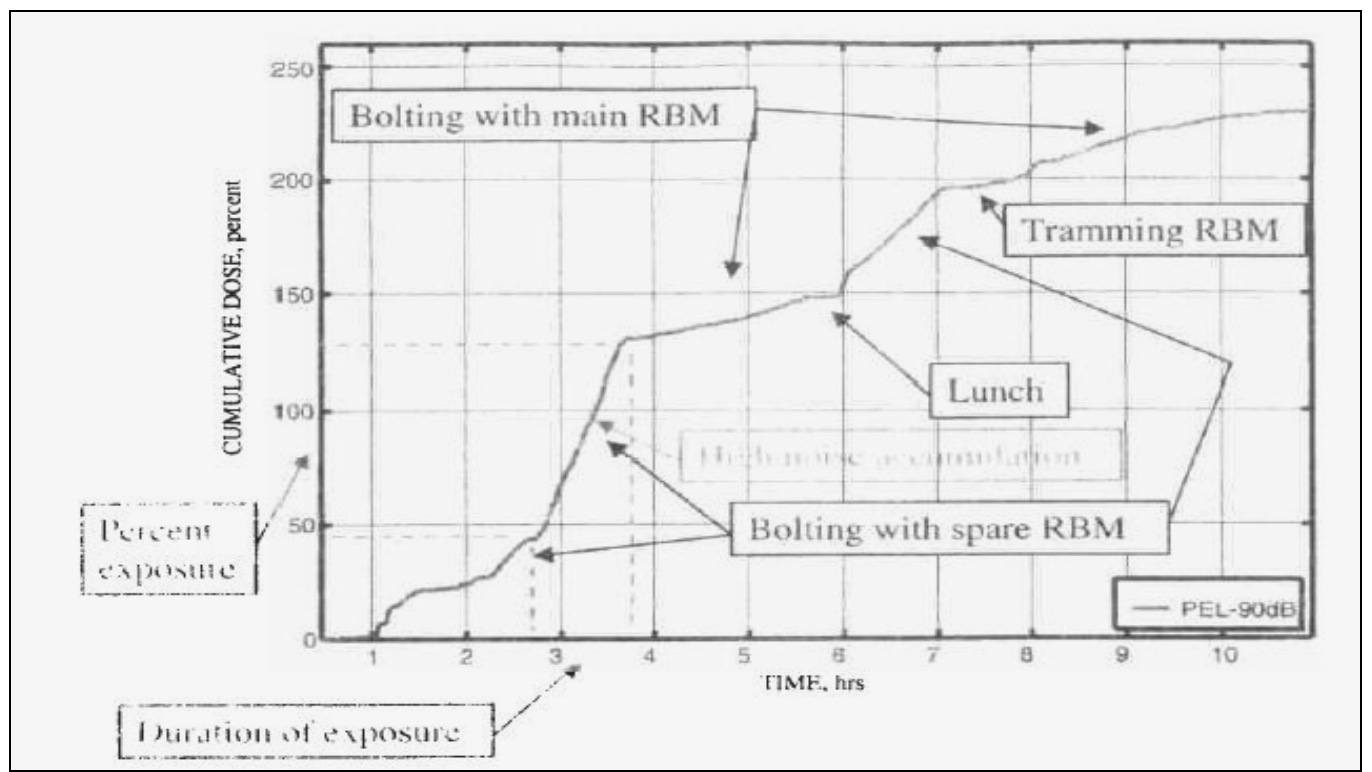

Figure 2.7 Cumulative dose plot for roof bolter operator., (Bauer and Babich, 2004).

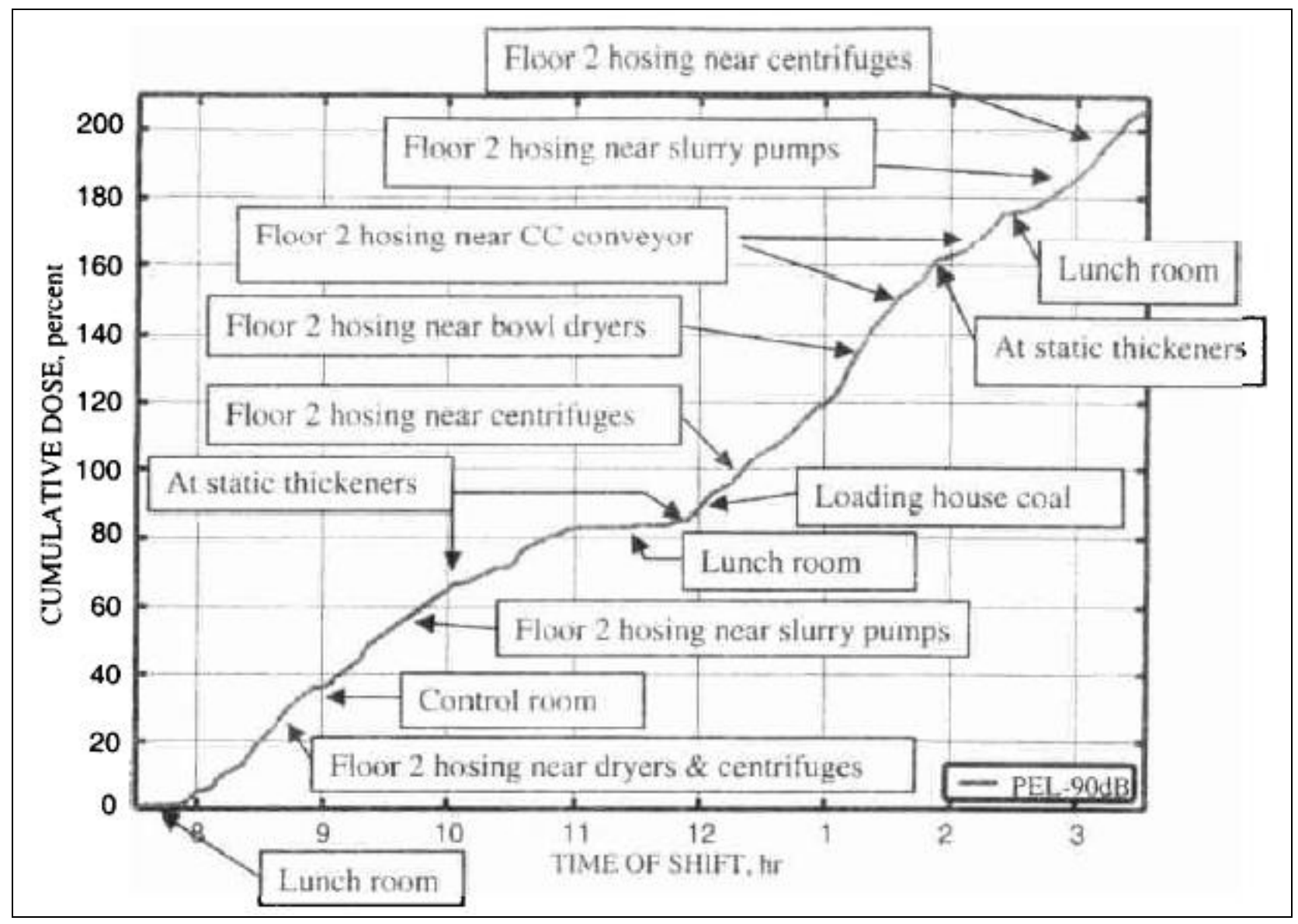

Figure 2.8 Cumulative dose plot for cell operator. (Bauer and Babich, 2004) 
This was a lucid method for task analysis and hence a proper selection of administrative measures can be adopted to avoid overexposure time for related tasks. The suggested remedial measures to deal with the NIHL include, change in time of exposure, passive noise control methods (Bauer and Babich, 2004), and ultimately developing engineering controls e.g. active noise control technology.

NIOSH's hearing loss prevention branch explained the study done by the group on continuous miner conveyors (Yantek, 2005). Here a polyurethane coating was applied to the flight bars of a JOY continuous miner conveyor. A 7-8 dBA reduction was observed when SPL was measured in NIOSH's reverberation chamber. When measurement recorded in an underground coal mine near the tail section of the continuous miner the noise was reduced by 4-6 dBA when flight bars were coated with polyurethane material. The below figure 2.9 shows coated flight bars put to the test.

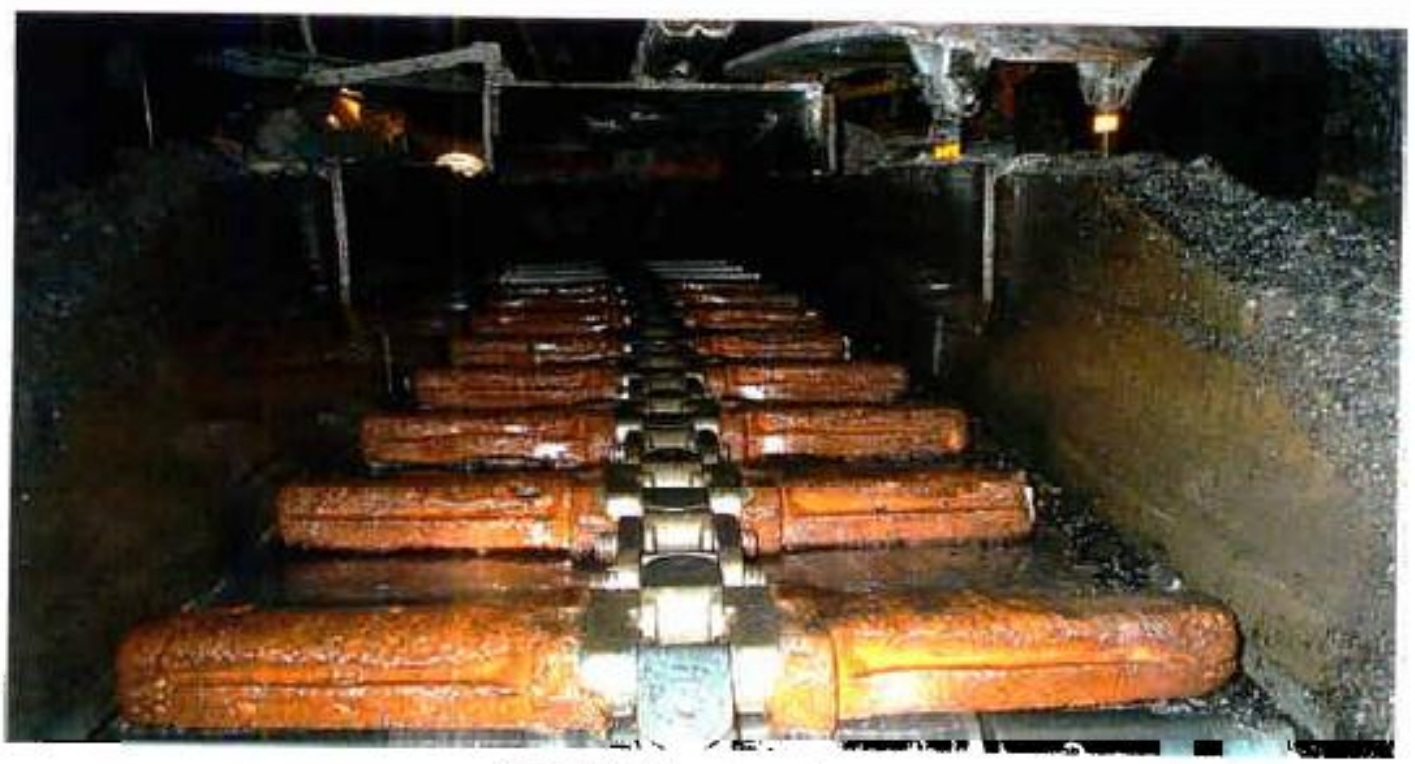

Cooted fight bars put to the test.

Figure 2.9 Polyurethane coated flight bars (Yantek, 2005).

Snyder, et al. ((2003) also developed a system to engineer an ANC in the mining environment. The experiments done by them showed a significant reduction 
in the single tone frequencies and some of the lower frequencies. Also, Hansen conducted ANC experiments in a cabin of a mining vehicle. Fig. 4 and Fig. 5 show the result for the experiment in the vehicle cabin. Though the work was inspiring but they failed to produce a good result for the random noise and high frequencies. He presented a relation about the wavelength and ANC work function. According to this research a frequency of certain dimension can only be canceled and above that the ANC become ineffective. More about this will be discussed in chapter 4 .

After analyzing the past works in this chapter, the following important points can be summarized:

- Most of these works followed the traditional method of data collection.

- Very few researchers tried to cover the frequency analysis at the various locations.

- Sound pressure profiles were developed for mining machines were used to understand the nature of noise in the underground mining conditions and its propagation pattern. Theses sound pressure profiles were used to determine sound power sources of various machine.

- For active noise cancellation (ANC) technology, the range of low frequency values of overall SPL and their contribution must be found in field measurements. As different combinations can be obtained in the ANC set up, as many combinations as possible must be considered in the ANC set up. 


\section{NOISE SURVEY AND CHARACTERIZATION OF
NOISE FIELDS}

\subsection{Introduction}

This chapter mainly discusses the noise surveys undertaken for this research to characterize and map the noise in and around longwall faces. The noise behavior is very complex and the noise field which is reverberant in the case of underground mining makes the issue more complex to analyze. Every effort is made to get and use latest available sophisticated gadgets in the measurement and analysis procedures. Also, MSHA has published new noise standards for mining (Federal register, 1999). The new law came into force on September 13, 2000. It adopts provision similar to U.S. Occupational Safety and Health Administration's (OSHA) hearing conservation amendments. The added requirements of the regulations are a permissible exposure level (PEL) of $90 \mathrm{dBA}$ time weighted average for 8 hours (TWA8). No credit is allowed for the use of personal hearing protection, feasible use of engineering and administrative controls for noise exposure reduction are encouraged. Survey was performed with compliance of new MSHA regulation.

In this chapter also the important assumptions and conditions under which the results of the work are valid will be outlined in a lucid pattern. The major purpose of the current work is related to the effect of mine confinement and set-up on the properties of noise produced. The survey work will be explored and compared to the available database, if any. The interpretation from the noise characterization will be used as basic criteria for the purpose of design of active noise control technology (ANC). Hence, in-depth discussions of possible data analysis are covered in this chapter. 
Noise surveys have been conducted in two longwall mines that conduct their mining operations in the Pittsburgh coal seam with mining height ranging from 6.5 to $7.0 \mathrm{ft}$. One mine is located in northern West Virginia and another in eastern Ohio. The two mines had the same types of shearers and shields but with different stage loaders. The surveys include the noise exposure dosage for different machine operators, the sound pressure level (SPL) distribution around a number of mining machines, and the SLP and frequency relationship at the selected machines. The octave band data (SPL vs. frequency) are especially useful for the design of engineering noise controls. To accomplish the task, noise readings were taken distances from the source.

Fig. 3.1 bellows shows a setup in a longwall face. It has a shearer incorporating high horsepower ranging drums facing the coal face. The shearer loaders are set on the panline of an armored face conveyor (AFC), which is laid on the floor parallel to the faceline. The face conveyor is driven by motor; electrical controls are supplied by service machine. The coal at the face is cut by the shearer loader. Coal is loaded onto AFC and transported to headentry T-junction and then coal is dumped onto a stage loader, which in turn empties to the entry belt conveyor. Coal feeds onto section belt then to main belt and supplied to preparation plant. 


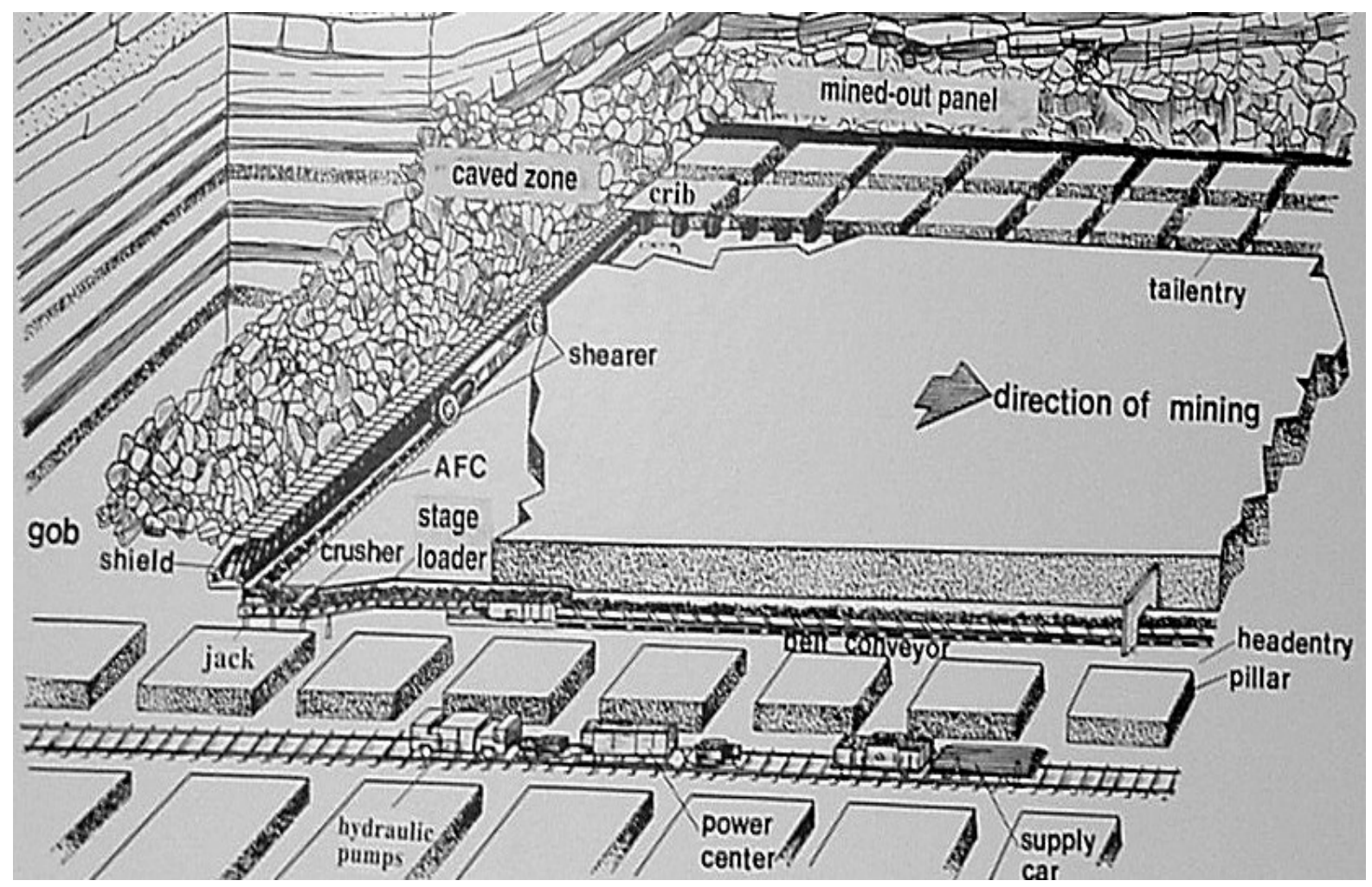

Figure 3.1 Typical longwall retreating panel layout (Peng and Chiang., Longwall Mining, 1984)

From the discussion it can be easily understood that Longwall mining face has energy intensive mining machines within a confined and congested area.

\subsection{Noise in Underground Coal Mining:}

The layout of underground mines shows that it is confined with limited option of space, the area is full of uneven surface and huge level of mechanization is employed to achieve high production. Among the working places in underground mining the Longwall mining faces could be noisier than other locations due to the use of heavy and energy-extensive machines in the rock breakage (cutting and crushing) and the haulage operations in the confined area. The typical setup in a longwall has chain conveyor, shearer, stage loader etc. The horse power energy consumed is high compare to underground mining operations. 
The characteristics of noise are very important factors responsible for the overall noise control process. The noise could be monotone or single tone comprising of one frequency and hence easier to process and control. But due mining conditions the noise produced is random noise. It consists of frequencies ranging from $20 \mathrm{~Hz}$ to $20 \mathrm{kHz}$. These frequencies are produced at different level at every point making the analyzing part more difficult. According to the theory of the noise, the directivity and reverberation interact with each other.

Mine Safety and Health Administration (MSHA) has published new health standards for occupational noise exposure (Federal Register, 1999) and it's effective from September 13, 2000. One of the significant changes is that every miner must be enrolled in a hearing conservation program (HCP) if his full-shift noise exposure is at or above the action level of 85 dBA TWA ( $8 \mathrm{hr}$ ) or $50 \%$ dose. Also, under the new regulation Permissible Exposure Level (PEL) of $90 \mathrm{dBA}$ TWA ( $8 \mathrm{hr}$ ) is included and no credit is considered for use of personal hearing protection (PHP), and the primacy of engineering and administrative controls for noise exposure reduction (Armour, 2003; McKinney, 2004).

From the Noise measurements taken in the US coal mines, the following points are worth noting:

- Need for more intense and regular noise database for all mines.

- Data indicates low frequencies are dominant frequencies. This trend is apparent for almost all machinery used in the mines.

- If possible new designs parameter should be selected at the manufacturing stage for different mine machinery.

\subsubsection{Works Performed}

The success of any noise control depends on accurate knowledge of the existing noise environment. Accurate surveys define areas within acceptable guidelines for noise exposure and those areas where potential harmful noise 
exposure exists. To make sure before going to survey what may be different situation for noise survey outlined. There are three types of sound fields i.e. near field, far or free field and the reverberant field. The below Fig. 3.2 explains:

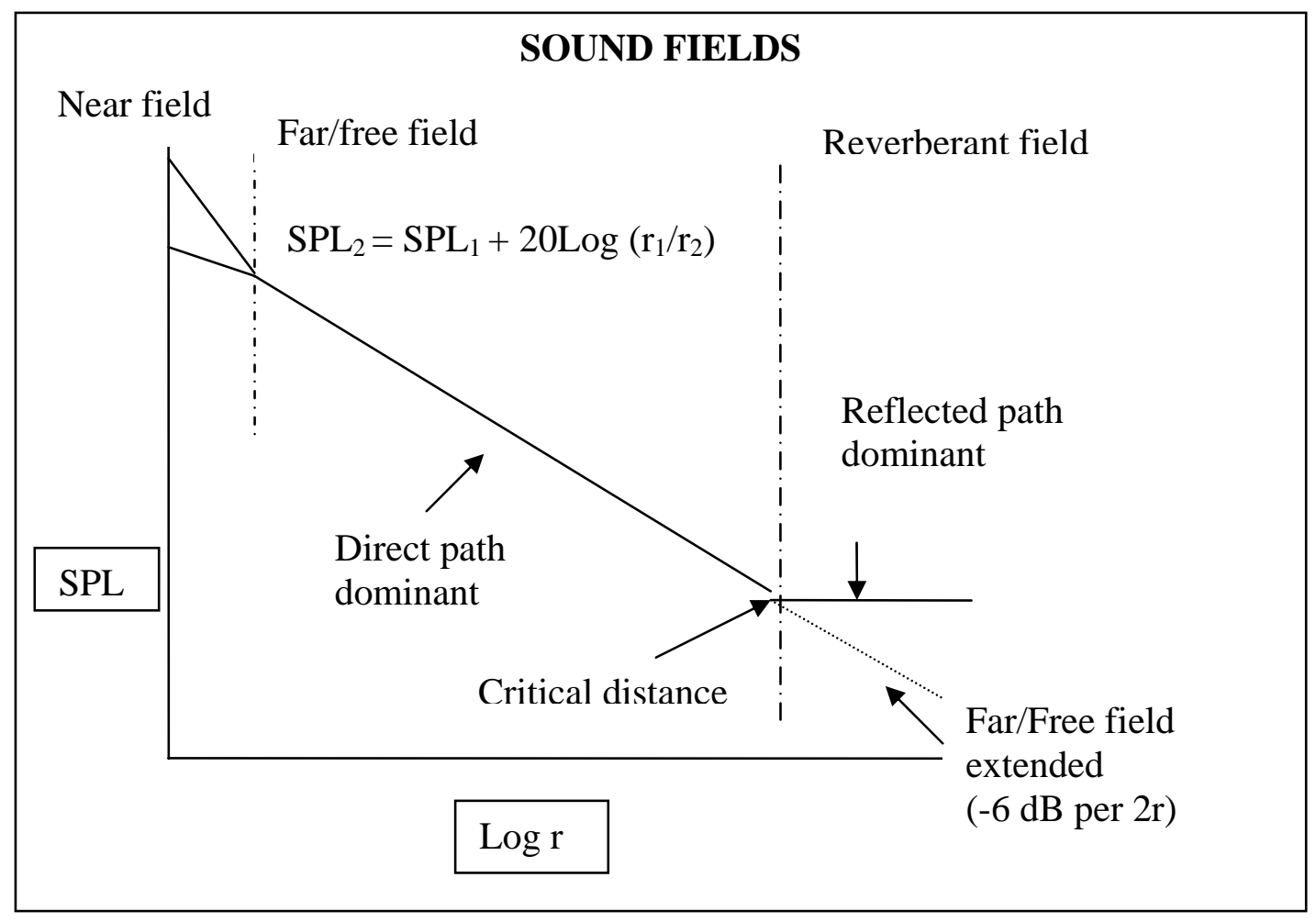

Figure 3.2 Sound fields (The Noise Manual, $5^{\text {th }}$ Edition., 2005).

The far field is defined as the area in which sound waves propagates uniformly from the source usually in space unencumbered by obstructions and reflections. The theoretical formula derived works very well in this area, where simply by conversion of energy as the wavefront in all directions SPL at a point can be estimated. SPL decrease by $6 \mathrm{~dB}$ by doubling of distance.

The near field is observed in the area close to the source, generally one wavelength distance of the dominant frequency and the wavefront still adjusting. Due to the unstable wavefront near field is unpredictable and may not follow the theoretical formula of far or free field. The reverberant field is the region where the reflected noise is close enough to the direct path noise and adds the reflected wave to overall 
SPL. Sorting accurate sound field is one of the important parameters for selection of effective noise controls.

\subsection{Proposed Work}

The noise pattern underground mining is very unpredictable and no known methods are available to accurately predict them without field measurements or observations. Generally noise survey used to record the overall SPL and perform OBA analysis as per need; assumptions are also made about the reflection and other underground parameters like temperature, humidity, and dust etc components effect on the noise.

\subsubsection{Field Noise Surveys}

The standard operating procedure for noise survey was outlined. It included both on the proper instrument calibration and noise measurement techniques. Instrument handling and data collection were performed as per the industrial standards. From the previous experiences of various researchers a format of noise recording table was outlined and hence used in the field surveys. Longwall coal mine is a different world in itself. All the different possible variation in the survey was studied and proper arrangement was made. Hence, it is important to consider the variation of number of parameters to achieve and stimulates practical noise environments from the measurements.

Quest Model 2900 Sound Level Meters (SLM) were used to measure noise levels in the mine. The SLM was handheld, with the microphone angled 70 degrees from the source and facing to the source. An A-Weighted equivalent Continuous Sound Level (Leq) measurement was recorded at each location. The A- Weighted Leq in decibels $(\mathrm{dB})$ is the average sound level for a measurement period based on a 3 (or 5) $\mathrm{dB}$ Exchange Rate and is a reflection of the human ear's auditory capabilities. A slow response rate with a time constant of 10 seconds was also employed. 
Following are the range of instruments used in the noise survey:

1) Quest Technologies, Sound Level Meter (SLM), 2900.

2) Quest Technologies, 1/3, 1/1 Octave Band Analyzer (OB300).

3) RCX-220 Digital Noise Recorder.

4) Digital Watch.

The equipments used during the noise survey are shown in Fig. 3.3. Quest Noise Dosimeter was used to monitor worker noise exposure. Dosimeter was set to monitor MSHA's Permissible Exposure Level (PEL) was set.

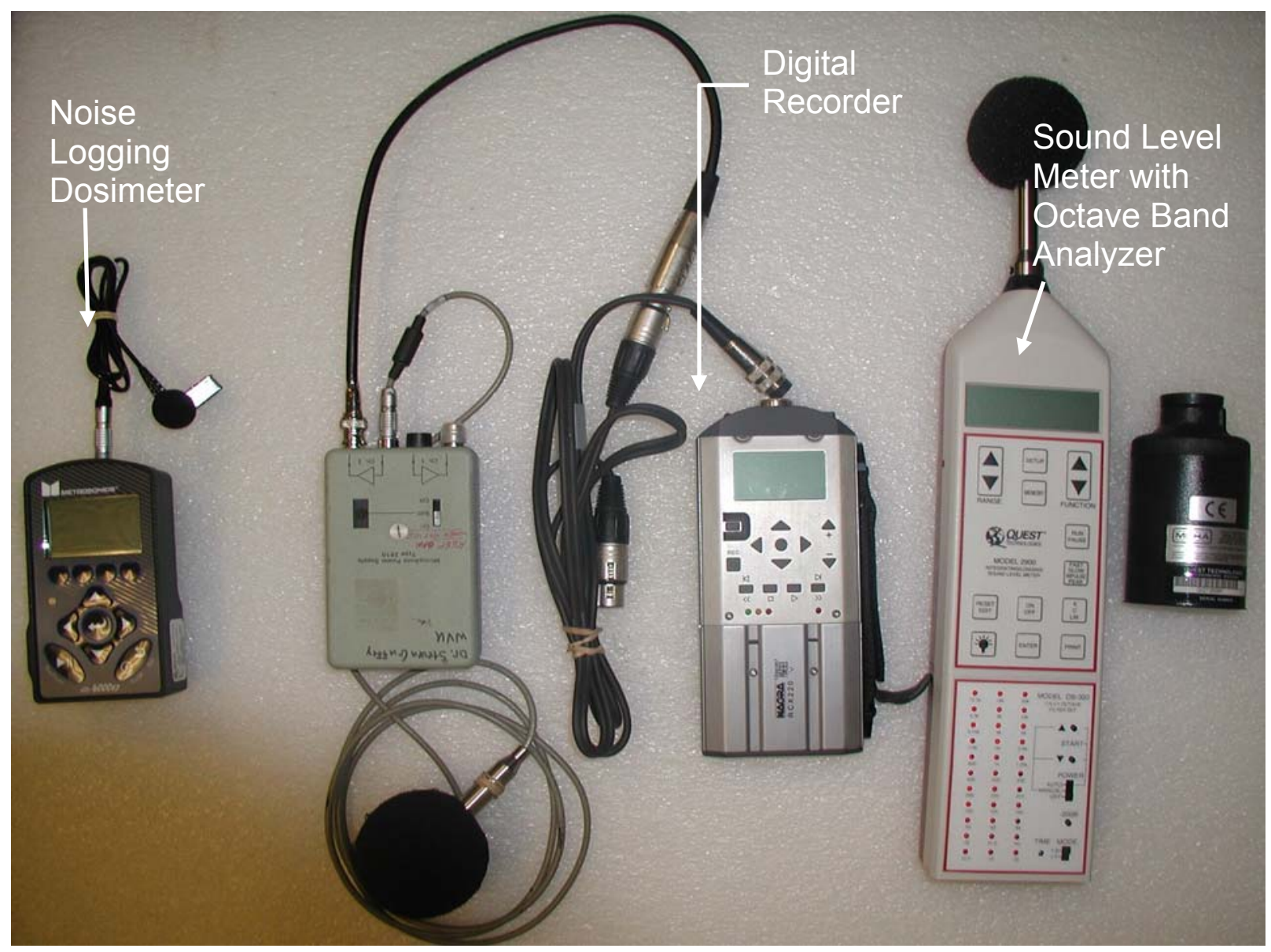

Figure 3.3 Noise Survey Equipment 
The characterization of noise sources on and around the longwall was complicated by the fact that the equipment is nearly always in motion, is comprised of many noise sources, and is loaded with varying amount of coal. Noise survey was performed in different stages. In the first stage the SLM was used to record the noise at the various positions in and around the longwall face. The survey results are used to plot the profile of SPL in the area. The second stage was to perform 1/3 octave band analysis (OBA) at various points of interest in the face. The OBA analysis helped to collect data for spectral analysis of the acoustic energy distribution in the possible frequency range. To cover the noise exposure by task analysis dosimeter was used to record minute by minute SPL. Source exposure time was recorded so that estimate of dose can be calculated.

- SLM 2900 and 5 sets of dosimeter were used at different points.

- RCX220 was used to record noise at various points and then analyze data with the help of OROS NV-GATE analyzer.

- Leq noise level values were recorded for the area around the stageloader, longwall hydraulics, face conveyor (panline), shearer, and the panel belt.

\subsubsection{Noise Survey at Mine A}

A longwall mining face area has energy intensive mining machines like shearer loader, AFC and stage loader. All these machines are placed within a confined and congested space. It is most likely due to many surface convolutions on the side walls, the roof and the floor; sound waves are diffusely reflected. The distributions of the A-weighted sound pressure levels along the crusher/stage loader (about $49 \mathrm{~m}$ long) in longwall face from two surveys are shown in Fig. 3.4 Both surveys show the similar distributions indicating that the sound field at this machine would not vary significantly. High SPL were recorded at drive end and transfer point of the stage loader. The peak sound level around the tailpiece end ranged from 98 to $104 \mathrm{~dB}$. A zone where the noise level is much lower than $90 \mathrm{~dB}$ is located in the gooseneck and control panel section of the machine. 


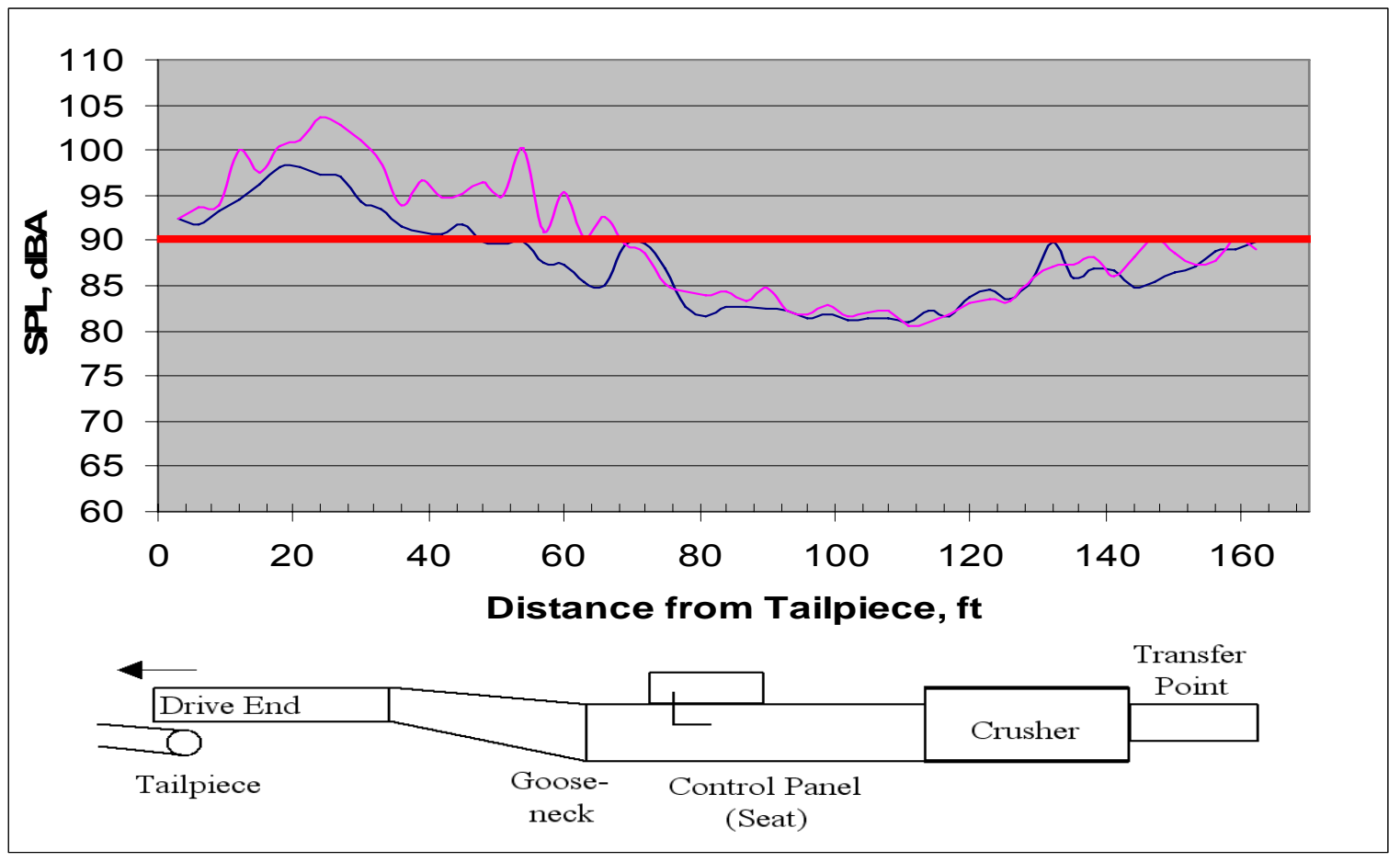

Figure 3.4 Noise Level at Different section of a Stage Loader

Hence measured sound pressure level (SPL) distributions along the stage loader suggested the following points:

- The measurements of SPL (ranging from 98 to 104 dBA) could be potential sources of over noise exposure.

- Higher noise levels exists at the tailpiece side of the stage loader,

- Data reveals a low noise zone in the gooseneck and control panel portion of the machine.

The contribution to noise dose from the various tasks of the headgate operator during the survey is shown in Fig. 3.5. It shows that the headgate operator would be exposed to a sound pressure level between $90 \mathrm{~dB}$ and $98 \mathrm{~dB}$ in the normal operation time. Occasionally, when the longwall face was not producing coal but the AFC, crusher and the stage loader were still running empty, the noise level in and near the headgate T-junction would be very high. Fig. 3.5 shows the sound pressure 
level could peak at $105 \mathrm{~dB}$ in such situation. However, such situation would be relatively short and would not contribute significantly to the cumulative noise dose to the operator.

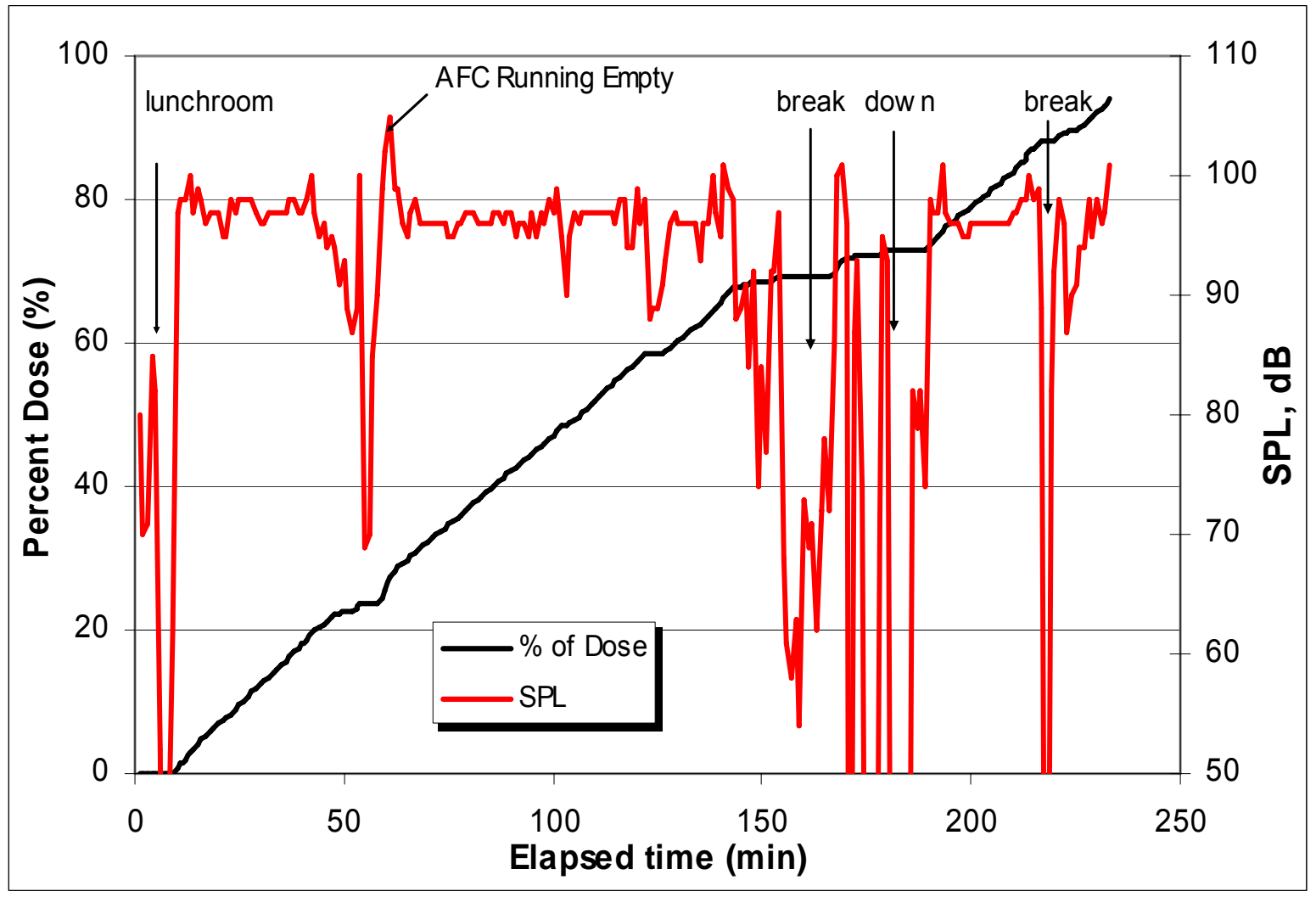

Figure 3.5 Noise exposure dose for headgate operator at the stage loader 
A typical dose accumulation for the shearer operators is given in Fig. 3.6. It shows during the coal cutting operations, the shearer operators were exposed to a noise level between 90 and $100 \mathrm{~dB}$. The duration, average sound pressure level and the cumulative noise dose at different activities for the tail shearer operator are summarized in Table 3.1. Both Fig. 3.6 and Table 3.1 show that the main sources of the noise dose were the coal cutting.

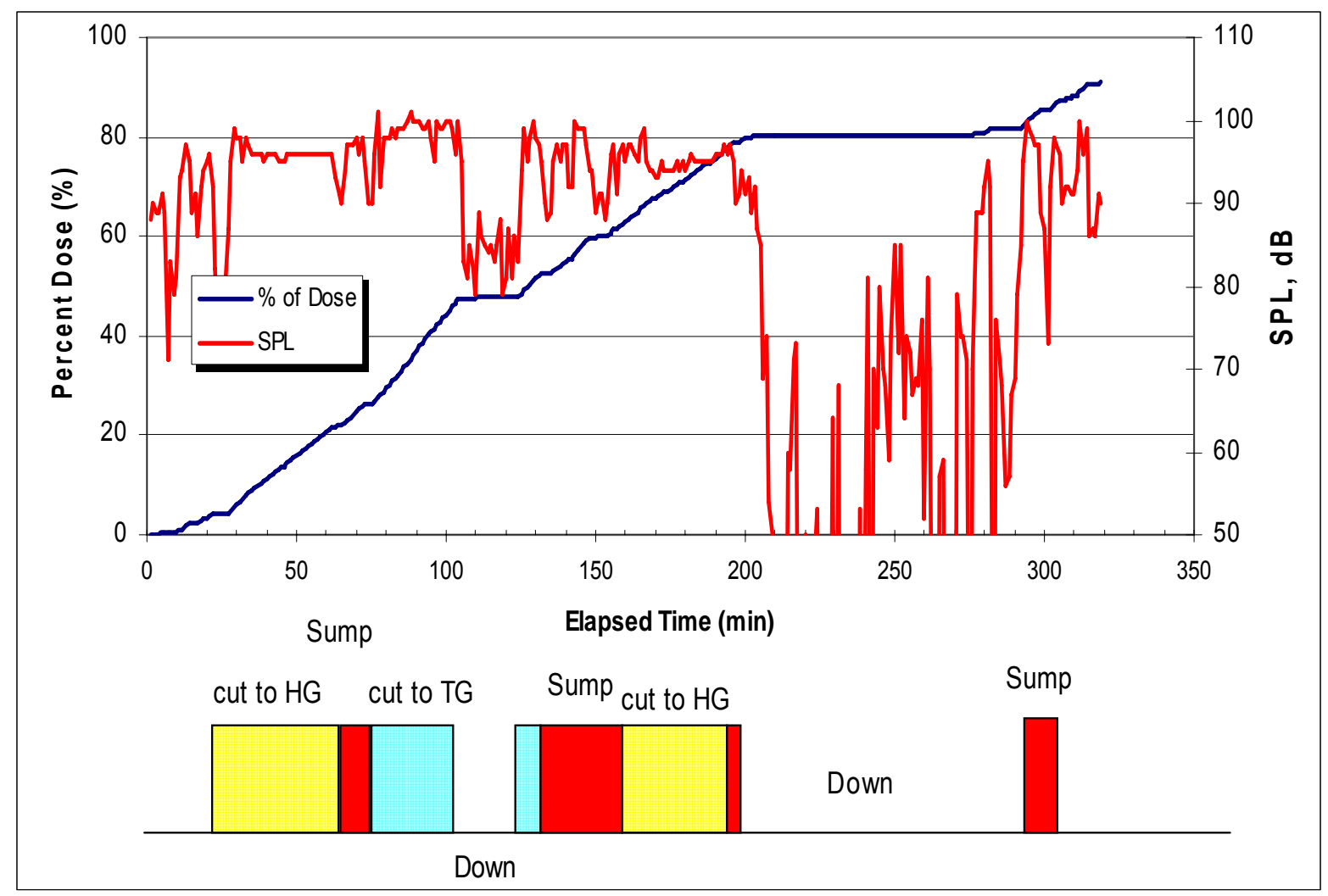

Figure 3.6 Noise exposure dose for tailgate shearer operator 
Table 3.1 Dose contribution and SPL by Activities for tailgate shearer operator

\begin{tabular}{l|c|c|c}
\hline \hline Mining Activities & $\begin{array}{c}\text { Duration } \\
\text { min. }\end{array}$ & $\begin{array}{c}\text { Average SPL } \\
\text { dBA }\end{array}$ & $\begin{array}{c}\text { Sum of Dose } \\
\%\end{array}$ \\
\hline Control Panel & 8 & 84.6 & 0.8 \\
\hline Shut Down & 122 & 79.6 & 6.0 \\
\hline AFC Run Empty & 11 & 85.3 & 1.2 \\
\hline Cutting to HG & 69 & 95.7 & 31.6 \\
\hline Cutting to TG & 34 & 98.6 & 23.3 \\
\hline Sumping @ HG & 38 & 94.6 & 15.0 \\
\hline Sumping @ TG & 37 & 93.8 & 13.0 \\
\hline \hline
\end{tabular}

Fig. 3.7 shows the results of the octave band analysis of the noise surveys at different locations along the stage loader. It reveals that the frequency distribution of the prominent sound pressure levels occurred within the 20 to $2,000 \mathrm{~Hz}$ range at the location of the tailpiece (exit end). At the other locations, the dominant frequencies are narrowed to between 20 and $1,000 \mathrm{~Hz}$. The underground surveys also found that the range from $100 \mathrm{~Hz}$ to $650 \mathrm{~Hz}$ is consistently the dominant noise frequencies in the longwall faces. 


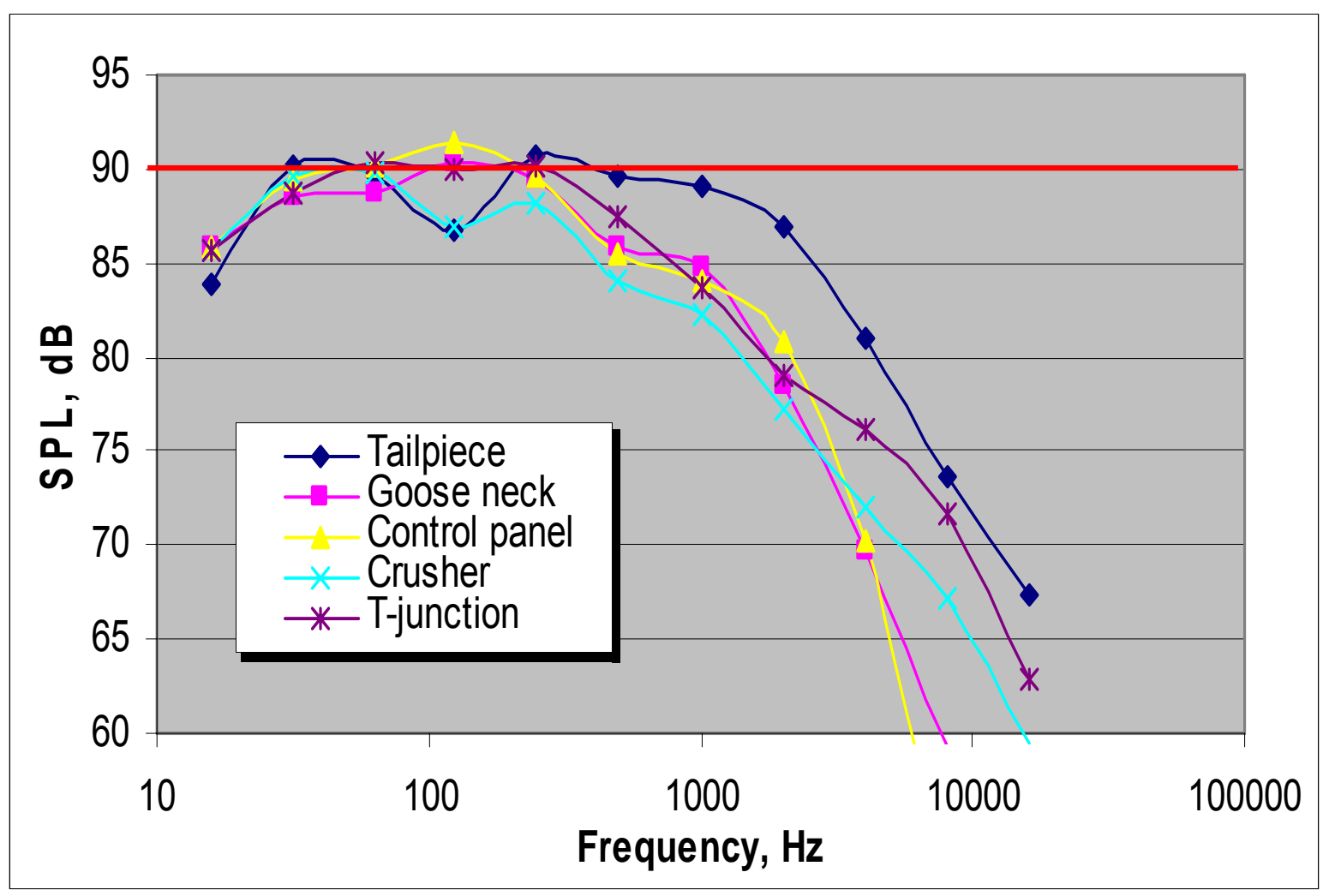

Figure 3.7 Results of octave analysis of the noise field along the stage loader 
Summary for octave band analysis for stage loader noise:

- There was significant overall noise.

- The different sections of the stage loader had different noise level.

- The frequency distributions were very significantly related to overall SPL.

- The behavior of lower frequencies was dominant. The dominant frequencies in the longwall faces: $100-650 \mathrm{~Hz}$.

The dosimeters were set at a criteria level of the $90 \mathrm{dBA}$ permissible exposure limit (PEL) with $5 \mathrm{~dB}$ exchange rate and $90 \mathrm{dBA}$ threshold cutoff. The estimated dose for full shift (8-hour) was calculated. Also, proper care was taken to record minute by minute position and activities of the workers wearing dosimeters. This helped the data correlate the noise sources they were exposed to sound pressure level and octave band measurements made of those activities and sources.

\subsubsection{Noise Survey at Mine B}

A comprehensive set of noise surveys were conducted in the mine B. This survey was more intense and focused on the following two objectives:

(1) To identify the mining machines, causes and operating conditions that produces the noises,

(2) To collect data for spectrum analysis - acoustic energy distribution in the possible frequency range for proper selection of noise control measures.

To analyze the task contribution to overall noise dosimeter were matched with timing and positions of the particular noisy sections. Details pertaining to the survey and points selected are provided later in this chapter. For purpose of the current work, the survey is divided in two steps, first include the SPL data and the other include the $1 / 3$ OBA at various sections of the mine. The length of the stage loader was $80 \mathrm{ft}$ as compare to stage loader of mine A, which was $140 \mathrm{ft}$. The survey output was analyzed and interpreted.

The figure 3.8 presents two sets of SPL data along the length of the stage loader. Similar SPL distribution pattern was observed. 


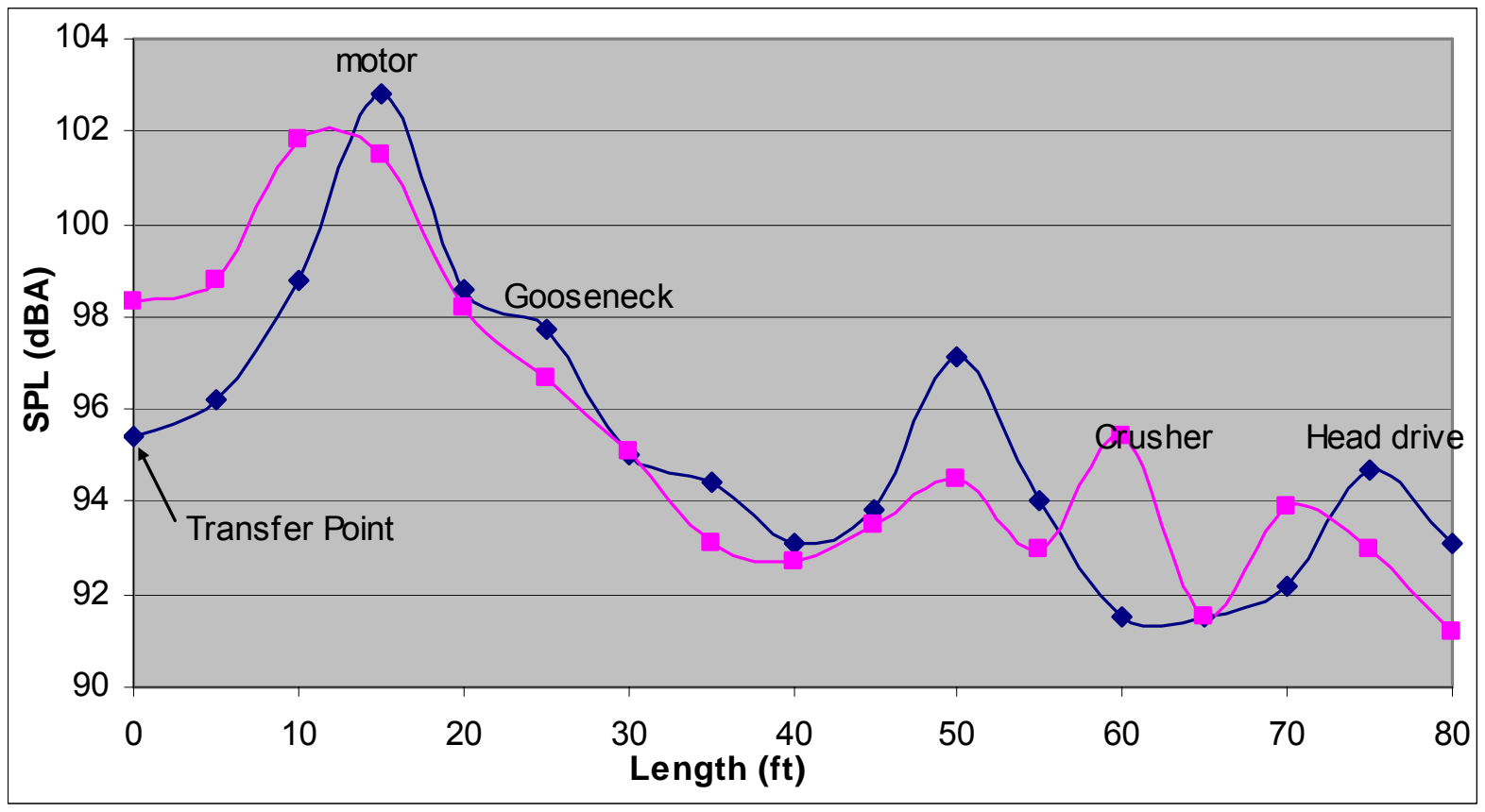

Figure 3.8. Overall SPL aligned with Length of the Stage Loader.

The Motor section SPL ranges from $98 \mathrm{dBA}$ to $102 \mathrm{dBA}$. Goose neck ranges anywhere from 94 to $98 \mathrm{dBA}$. Crushes section contributes 91 to $94 \mathrm{dBA}$ noise level in the Longwall section. Head drive part of stage loader has 91 to $93 \mathrm{dBA}$ noise level. It was also observed that higher noise levels were present at the end of the machine, especially motor on the tail piece side and the gooseneck. The central portion of the stage loader experienced a low noise zone. Since these certain locations are the highest noise sources, octave band analysis was focused on these locations. The brief discussion of OBA data is presented in the OBA section later in this chapter. 
In the case of noise in the entry and its propagation, an attempt was made to record noise with respect to the distance away from the crossframe from the stage loader. Fig. 3.9 reveals the natural phenomenon that noise dies as it moves away from the source i.e. stage loader. This figure also shows that the SPL values of the individual components of the mine entry will be different. In this $200 \mathrm{ft}$ noise survey section, the lowest value is $82 \mathrm{dBA}$ and the highest is $103 \mathrm{dBA}$. The range of difference is $20 \mathrm{dBA}$, which is significantly high.

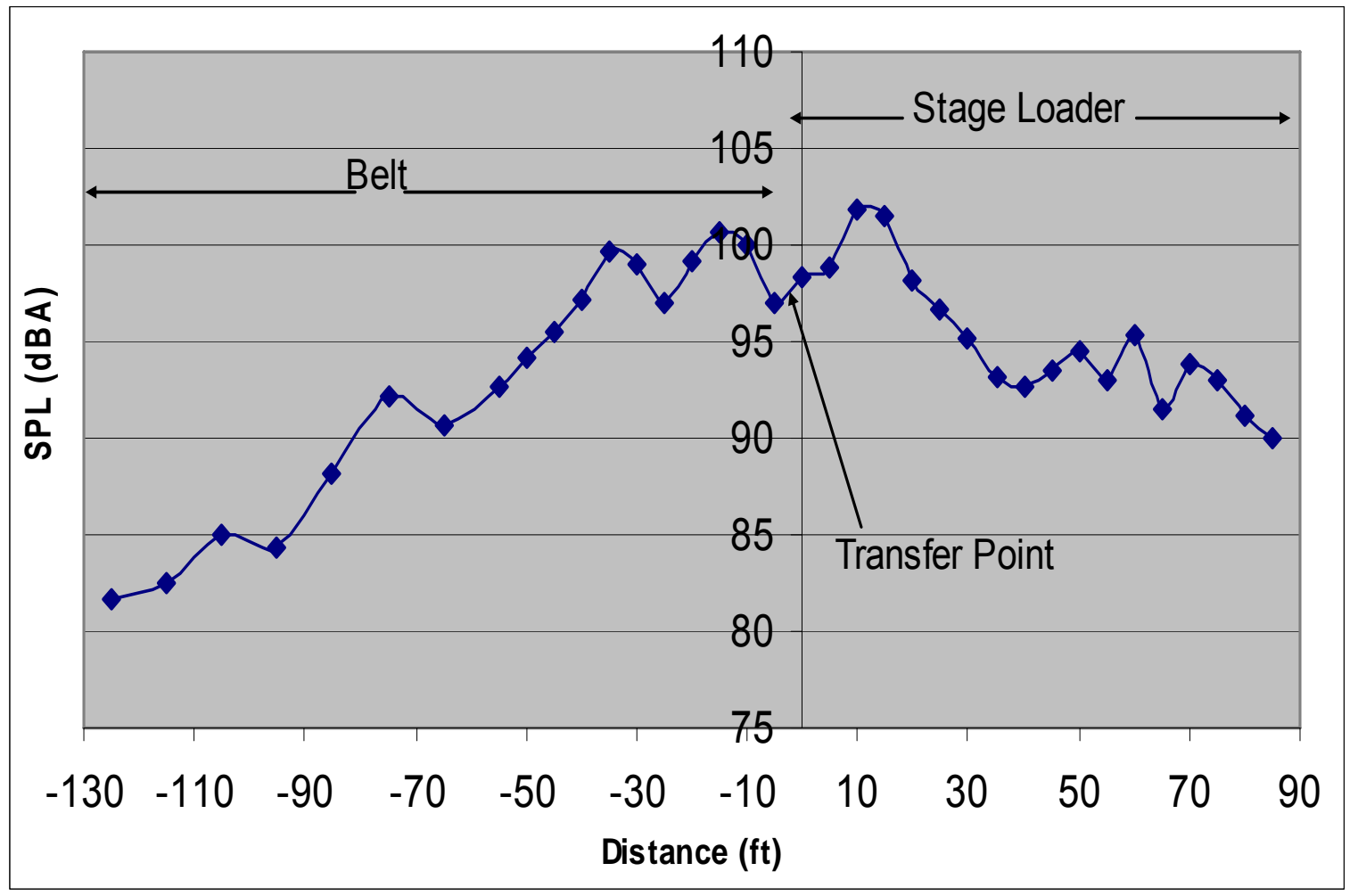

Figure 3.9 SPL along the Stage Loader Section 
Noise Survey in the crosscut:

The noise survey was carried out in the last open crosscut and in the track entry. The survey was divided into two sections in the last open crosscut $(A)$ and in the track entry (B) as shown below in the Fig. 3.10. The A section covered the full length of the crosscut. Sound level meters were used to measure the overall SPL and also octave band analysis was done at various points of the sections $A$ and $B$ respectively.

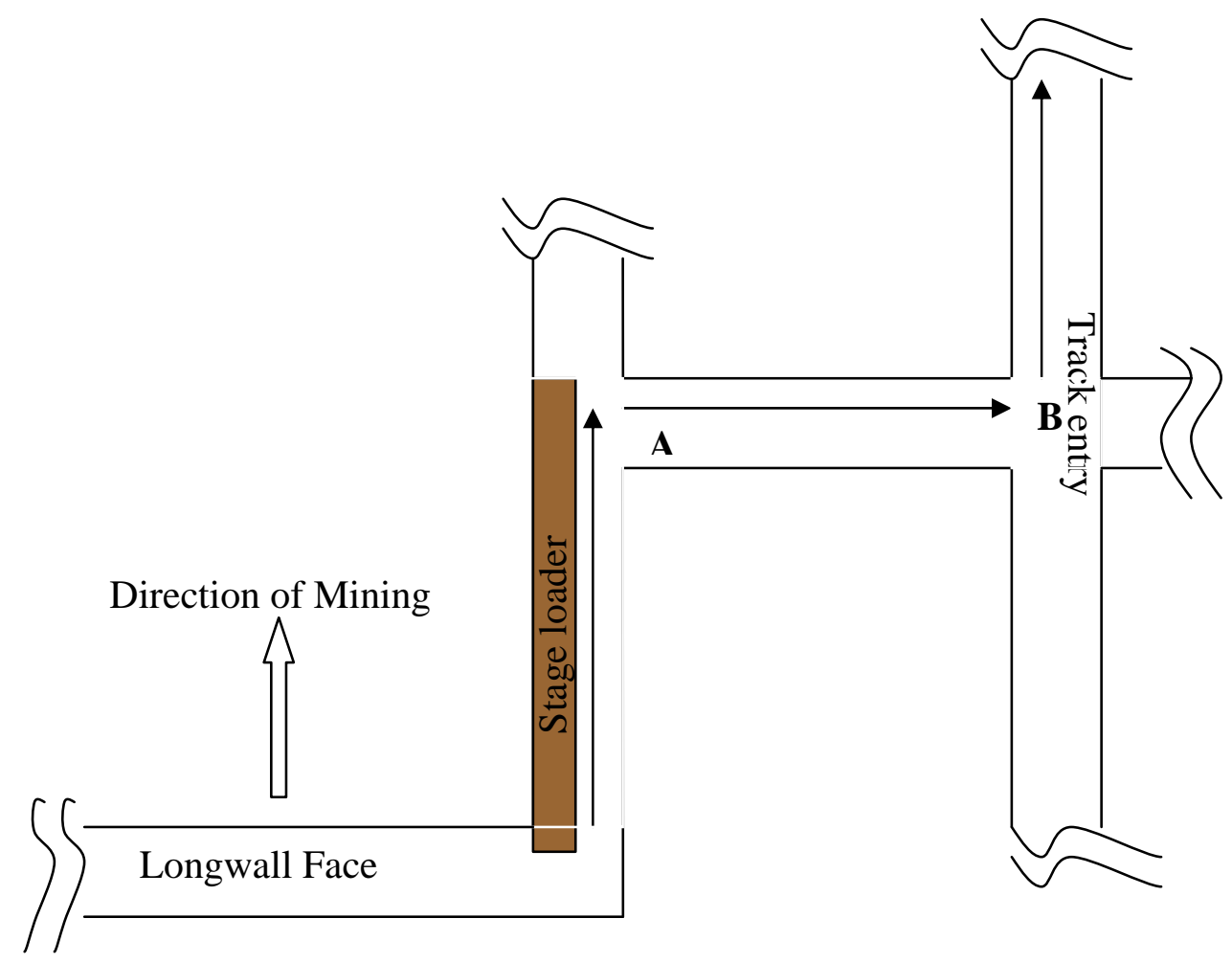

Figure 3.10 Overall SPL aligned with Length of the Stage Loader 
Table 3.2 shows the SPL values in the entry; it ranges from $77 \mathrm{dBA}$ to $96 \mathrm{dBA}$ in the section $A$ and 61 to $76 \mathrm{dBA}$ in the section $B$ of the survey.

However the noise survey on the longwall face revealed a different picture. The SLM was used to measure overall SPL with respect to the shield numbers. Also, minute by minute data was recorded using dosimeter at various points. Some points were also used for octave band analysis.

Table 3.2 Cross Cut Noise Survey

\begin{tabular}{|c|c|c|c|c|c|}
\hline Position & Length(ft) & SPL(dBA) & Position & Length(ft) & SPL(dBA) \\
\hline A & 5 & 95 & B & 10 & 76.2 \\
\hline A & 10 & 96.2 & B & 20 & 75.7 \\
\hline A & 15 & 90.6 & B & 30 & 71.9 \\
\hline A & 20 & 90.4 & B & 40 & 70 \\
\hline A & 25 & 87.4 & B & 50 & 68.1 \\
\hline A & 30 & 87.5 & B & 60 & 66.6 \\
\hline A & 35 & 86.2 & B & 70 & 64.2 \\
\hline A & 40 & 83.1 & B & 80 & 64.1 \\
\hline A & 45 & 77.6 & B & 90 & 63.3 \\
\hline Edge of Pillar & 50 & 78.4 & B & 100 & 63 \\
\hline $\begin{array}{c}\text { Center of Track } \\
\text { Entry }\end{array}$ & 60 & 76.8 & B & 110 & 61.4 \\
\hline & & & $\begin{array}{c}\text { Center of next } \\
\text { outby cross cut }\end{array}$ & 120 & 59.2 \\
\cline { 5 - 6 } & & &
\end{tabular}


Fig. 3.11 represents the SPL level changes at various shield locations when the shearer was 20 ' away. The two sets of data almost show similar pattern.

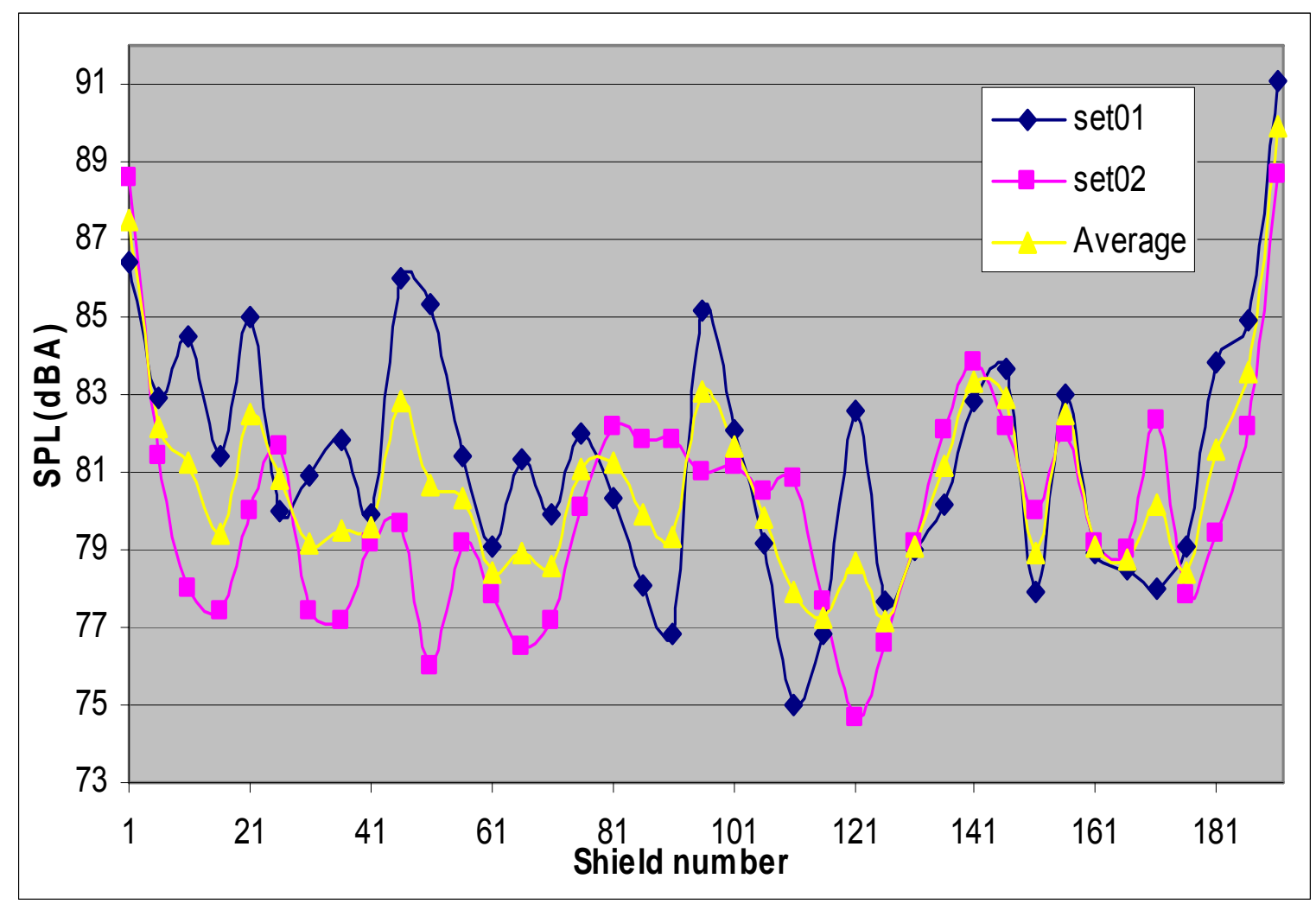

Figure 3.11 SPL at the Longwall Face with respect to Shield Number.

Octave Band Analysis:

The next step was octave band analysis of the noise present in the various sections of the longwall section. The OBA analysis provides details about the frequency spectrum and helps in determining the dominating frequency band. Table 3.3 provides the details about the $1 / 3^{\text {rd }}$ OBA analysis at various section of the stage loader. The stage loader is $60 \mathrm{ft}$ long with actual of $57 \mathrm{ft}$ long enclosure.

The tail motor sections showed $102 \mathrm{dBA}$, Gooseneck produced $98 \mathrm{dBA}$ and etc. In all the noise sources the dominance of lower frequency can be easily understood by observing Table 3.3. 
Table 3.3. Octave Band Analysis at the Stage Loader

\begin{tabular}{|c|c|c|c|c|c|}
\hline \hline & Tail piece & Tail Motor & $\begin{array}{l}\text { Goose } \\
\text { neck }\end{array}$ & $\begin{array}{l}\text { Control } \\
\text { panel }\end{array}$ & $\begin{array}{l}\text { Enclosure } \\
\text { entrance }\end{array}$ \\
\hline & $0 \mathrm{ft}$ & & $30 \mathrm{ft}$ & $45 \mathrm{ft}$ & $60 \mathrm{ft}$ \\
\hline dBA & 94.4 & 102.8 & 98.2 & 93.7 & 92.5 \\
\hline dBLin & 99 & 105.5 & 105.7 & 103 & 101.6 \\
\hline Freq. (Hz) & SPL, (dB) & SPL, (dB) & SPL, (dB) & SPL,(dB) & SPL, (dB) \\
\hline 16 & 85.7 & 92.5 & 91.5 & 95 & 91.4 \\
\hline 31.5 & 90.6 & 98.8 & 97.2 & 96.6 & 92.7 \\
\hline 63 & 93.3 & 96.9 & 94.7 & 94 & 92.3 \\
\hline 125 & 96.3 & 96.3 & 95.2 & 97.7 & 96.6 \\
\hline 250 & 92.5 & 99.3 & 93 & 93.7 & 92.1 \\
\hline 500 & 92.3 & 102.3 & 93.3 & 95 & 91.8 \\
\hline 1000 & 94.8 & 97 & 90 & 91 & 87.2 \\
\hline 2000 & 87.8 & 96.6 & 86 & 87.6 & 84 \\
\hline 4000 & 81.9 & 93.6 & 77.6 & 77 & 78.6 \\
\hline 8000 & 74.5 & 80 & 68 & 66.9 & 68.4 \\
\hline 16000 & 67.5 & 65.9 & 54.3 & 55.1 & 61.4 \\
\hline \hline
\end{tabular}


In the case of noise around longwall stage loader, the importance of low frequencies is understood and clearly demonstrated by Fig. 3.12. The analysis revealed that the frequency distribution of the prominent sound pressure levels occurred within the 0 to $2000 \mathrm{~Hz}$ range. It was also found that the $125 \mathrm{~Hz}$ to $1000 \mathrm{~Hz}$ are consistently dominant frequencies.

The octave band analysis of the frequency spectrum showed that the tail motor, tail piece, goose neck, control panel and the crusher section in the stage loader are dominated by high low frequency noise. All of them demonstrated similar pattern (Fig. 3.12).

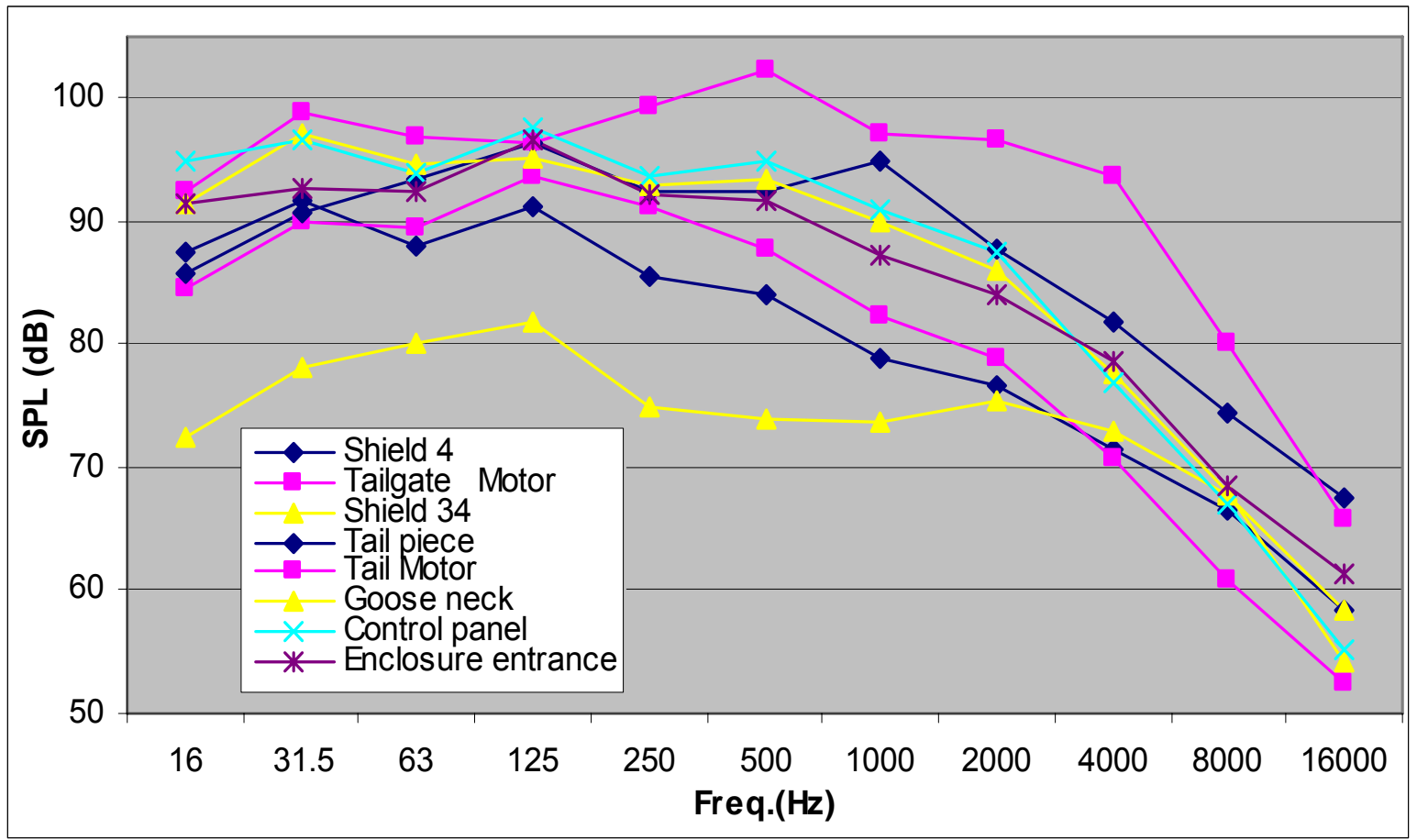

Figure 3.12 OBA along the Stage Loader at Mine B 
Table 3.4 OBA at the Headgate

\begin{tabular}{|c|r|r|r|}
\hline & \multicolumn{1}{|l|}{ Shield 4 } & \multicolumn{1}{l|}{ Tailgate } & \multicolumn{1}{l|}{ Shield 34 } \\
\hline dBA & & \multicolumn{1}{l|}{ Motor } & \\
\hline dBLin & 83.6 & 87.6 & 79 \\
\hline Freq (Hz) & S9.2 & 97.4 & 87.1 \\
\hline 16 & 87.4 & 84.6 & 72.4 \\
\hline 31.5 & 91.7 & 90 & 78.2 \\
\hline 63 & 87.9 & 89.4 & 80.1 \\
\hline 125 & 91.1 & 93.7 & 81.8 \\
\hline 250 & 85.6 & 91.3 & 75 \\
\hline 500 & 84.1 & 87.7 & 74 \\
\hline 1000 & 78.8 & 82.4 & 73.6 \\
\hline 2000 & 76.6 & 78.8 & 75.4 \\
\hline 4000 & 71.5 & 70.6 & 72.9 \\
\hline 8000 & 66.5 & 60.9 & 67.7 \\
\hline 16000 & 58.5 & 52.4 & 58.4 \\
\hline \hline
\end{tabular}

The OBA at the headgate showed an overall SPL of $83.6 \mathrm{dBA}$ at shield no.4, 87.6 dBA at tailgate motor and $79 \mathrm{dBA}$ at Shield no.34. A similar pattern of lower frequency dominance was observed at all of them (Table 3.4).

\section{Octave Band Analysis at the Power Pack Unit:}

Continuing the idea to characterize the mine noise, frequency analysis was performed on the power pack unit section. Figure 3.13 shows that the overall noise at the compressor was $96 \mathrm{dBA}$ and pumps produced a noise level of $100 \mathrm{dBA}$. 
Figure 3.13 shows that the overall noise at the compressor was high. The pumps which produced a noise level of $100 \mathrm{dBA}$ showed a considerably high value for the lower frequencies ranging from $125 \mathrm{~Hz}$ to $2000 \mathrm{~Hz}$.

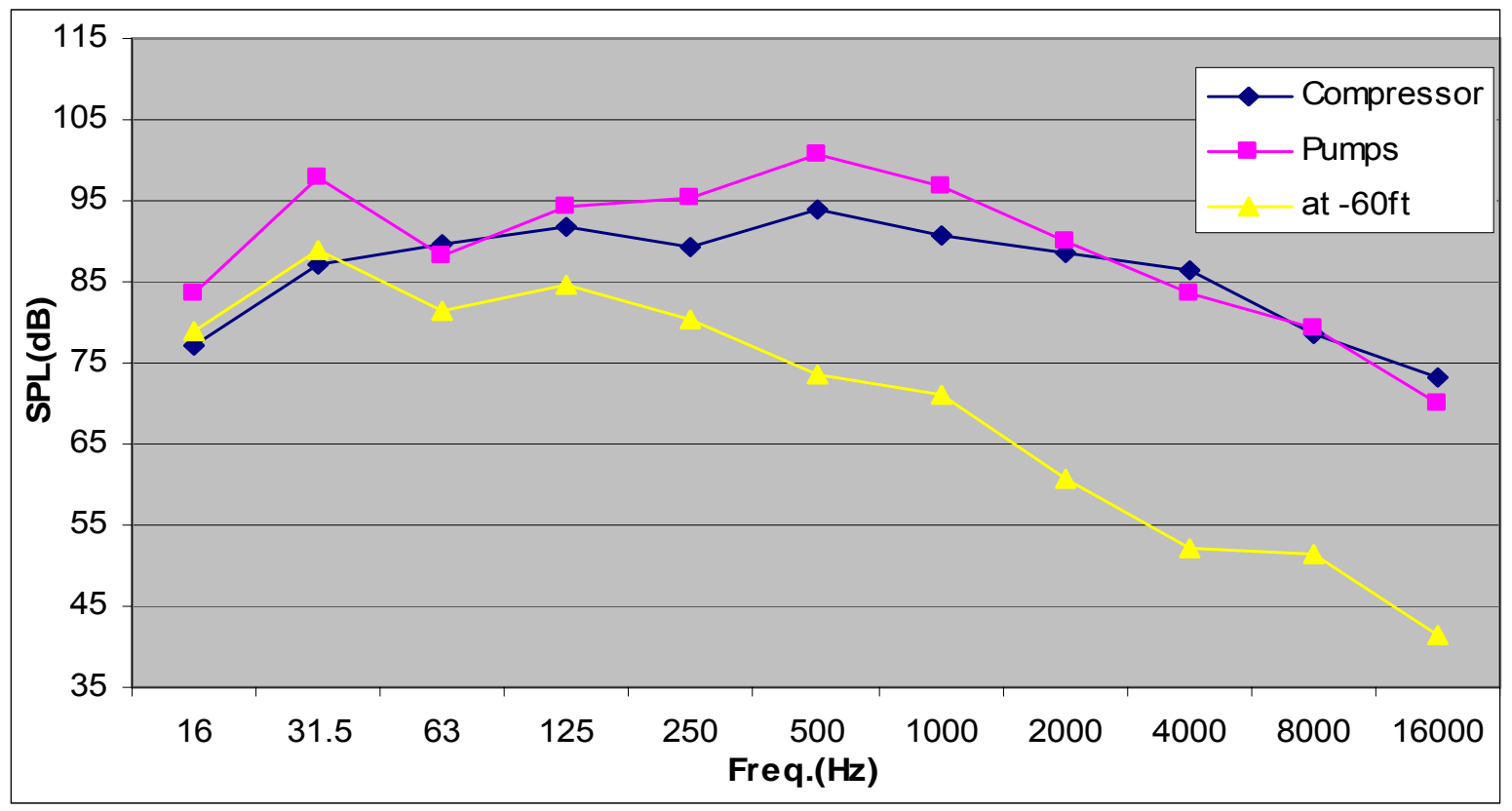

Figure 3.13 OBA at Power Pack Unit

Fig. 3.14 also proved the declining of the overall noise at a distance $60 \mathrm{ft}$ away from the power pack unit, which is a general phenomenon of sound. But the dominance of low frequency is still experienced. The shifting of high SPL to lower frequency at $50 \mathrm{ft}$ away from the power pack indicated that the entry surface absorbs high frequency sounds more than the low frequency ones.

\subsection{Summary}

Various noise survey methods are applied and have been compared and from the characterization graphs and data, it is clear that attenuation of signal with distance is frequency dependent, with stronger attenuation of higher frequencies with increasing distance from the source. Frequency dependence due to destructive interference also forms an important part of the weakening of a noise signal. 
In a mine environment where the surface is uneven and there are many sources of reflection therefore it is difficult to evaluate any particular relation between the attenuation rate and distance.

After the noise parameters and the characterization were determined, fundamental analysis was applied to the noise signals to show how the sound pressure level varied as a function of frequency. The analysis revealed that the frequency distribution of the prominent sound pressure levels occurred within the 0 to 2000 Hertz range. It was also found that the $125 \mathrm{~Hz}$ to $600 \mathrm{~Hz}$ are consistent dominant frequencies.

The noise results were further analyzed to determine the influence of various factors on the sound levels. Since the operations of the stage loader were not controlled in any particular manner, it was difficult to differentiate between the causes of the variability in the measured stage loader.

Both noise surveys were in the typical Pittsburgh seam geo-mining conditions used for the proposed research. The existence of low frequencies was found to be dominant well in both Mine A and Mine B regions. Thus with all these data and noise characterization study, a better understanding of reasonable solution and regulation needed is developed.

Therefore the approach with two applications is needed: (1) Controlling high frequency noise with passive control; (2) Canceling low frequency noise with engineering control (Active noise control). Since the Passive controls are not adequate enough to control the low frequency, it was decided to develop Active noise control technology in this research. 


\section{ACTIVE NOISE CANCELLATION TECHNOLOGY}

\subsection{Active Noise and Passive Noise Control Technology}

Based on the characteristics of the noise sources in the longwall faces, efforts have been made to develop engineering controls to reduce the noise levels for the major noise sources and the working locations where the miners spend most of their times. There are two possible approaches to reduce the noise: passive and active. The conventional noise controls are based on the passive approach such as enclosures, barriers etc to attenuate unwanted noise. However, they could be costly, require large space and are ineffective at low frequencies, making some of the passive control methods often impractical. In this work, the emphasis is placed on studying the applicability and effectiveness of the active noise cancellation (ANC) technology for the crusher/stage loader assembly - one of the noisiest machines in a longwall face.

Real-time active noise cancellation is a relatively new field in the mining industry even though it has been successfully applied in some other industries. The schematic drawing of ANC technology applied in the duct is shown in Fig. 4.1. As the source noise travels through a duct, it is detected by the input microphone and the electronic signal which is fed into the ANC controller. The characteristics (i.e., sound pressure level, frequency and phase) of the source noise are analyzed by the controller. The anti-noise (or control noise), similar to the source noise but in opposite phase, is generated by the ANC controller and speaker and released into the duct at proper location. The mixing of the source noise and anti-noise waves will result in a sound field with reduced sound pressure level (residual noise). 


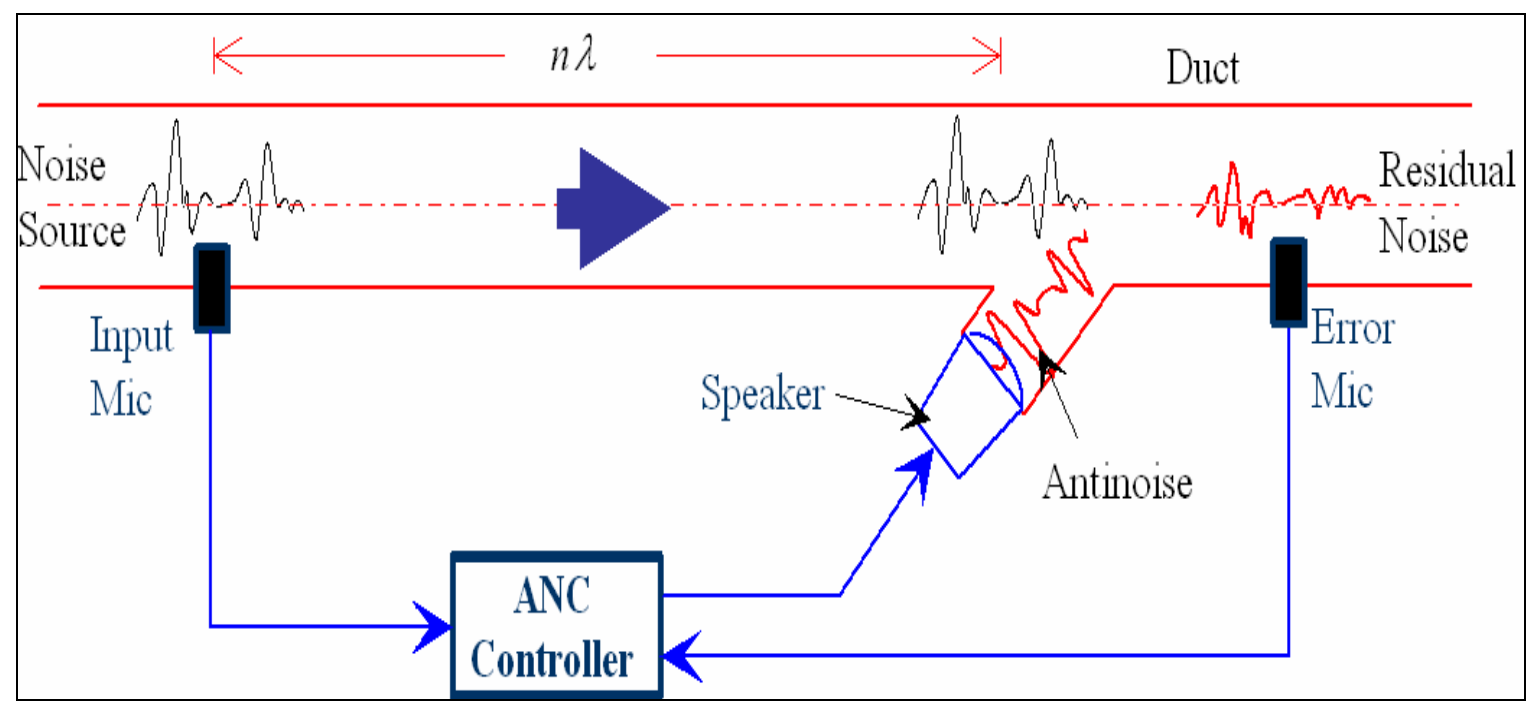

Figure 4. 1 Schematic of feed forward active noise control system in a duct

\subsection{LABORATORY NOISE SURVEY}

As stated previously, the engineering noise controls can be classified into the passive controls and active noise controls. Due to the impracticalities of using passive noise controls in reducing the low frequency noises - dominant for some of the longwall machines, emphasis of this research is to study the applicability and effectiveness of active noise controls (ANC) to some of the longwall machines. Among the machines, the crusher and stage loader assembly is selected as the target of the study for the following reasons:

- It is often one of the noisiest machines in and around the longwall faces.

- More workers will spend more working time in and near this location.

- In order to make a successful set-up, it is easy to create "ducts", with some minor and inexpensive changes to the machines that can maintain the "standing" noise waves required to apply the ANC technology successfully and effectively.

The ANC methods are most promising to attack the noise field in an enclosed

linear space, such as ducts, where noise standing waves can be maintained along its propagation path. A noise standing wave is that the characteristics of a standing 
(i.e., sound pressure level, frequency and phase) will maintain nearly unchanged along its path. By maintaining standing wave in a duct, the noise field becomes an essentially one-dimensional problem and can be attacked more readily using the ANC technology. In order to maintain such standing wave in the duct, the largest duct cross-sectional dimension of the duct should be one quarter of the wave length $(\lambda / 4)$ of the highest frequency of the noise to be reduced (Bies and Hansen, 2003).

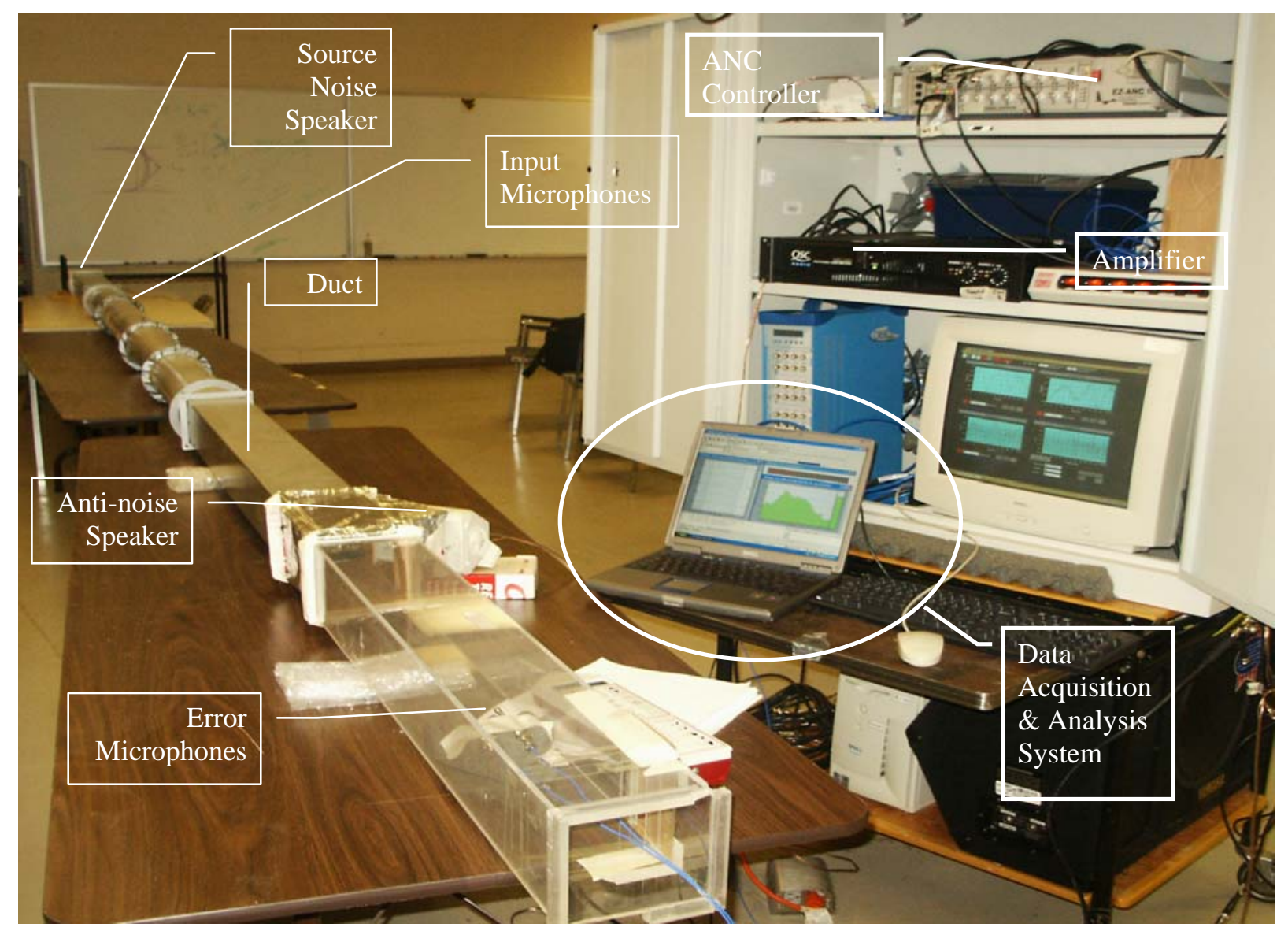

Figure 4.2 The laboratory setup for ANC experiment

As stated before, ANC technology could be successfully applied on those machines where the noise propagates in a "duct" of proper cross-sectional size. Among the machines in a longwall face, the crusher/stage loader assembly is considered as the best candidate for the application of ANC technology. Noises generated by the motors, the coal crushing actions in the crusher, and the rubbing actions between the flight bars and the pans travel inside the steel enclosure and 
exit at the both end openings. This phenomenon is clearly demonstrated in Fig. 3.4 where high noises SPL are located near both ends of the machine assembly compare to the middle portion. It must be noted that noise also radiates directly off of the crusher enclosure and the machine walls. However, this study is focused only on the internal noise source emitted from the ends of the machine - the main contributor to the noisy environment in the headgate T-junction area. The studies of applying ANC technology has been carried out in laboratory experiments in a steel duct that simulates the part of the open space on the carrying side of the stage loader.

Fig 4.2 shows the laboratory setup of the ANC experiment with a steel duct system used as the noise traveling path. In this duct system, both rectangular and circular ducts, with the same diagonal distance, are used. The previous research shows that the shape and surface do not affect the nature of the standing wave (Bies and Hansen, 2003). The rectangular portions of the duct were $11.4 \mathrm{~cm}$ wide, $12.7 \mathrm{~cm}$ high while the circular portion has a diameter of $17 \mathrm{~cm}$. Based on the $\lambda / 4$ rule, the shortest wavelength in the standing wave would be $(4 \times 17 \mathrm{~cm}=68 \mathrm{~cm})$. Therefore, the highest frequency of the noise that can be effectively cancelled in the duct will be $506 \mathrm{~Hz}$ since the speed of sound in air is $344 \mathrm{~m} / \mathrm{s}$. The length of the duct system was $6.3 \mathrm{~m}$.

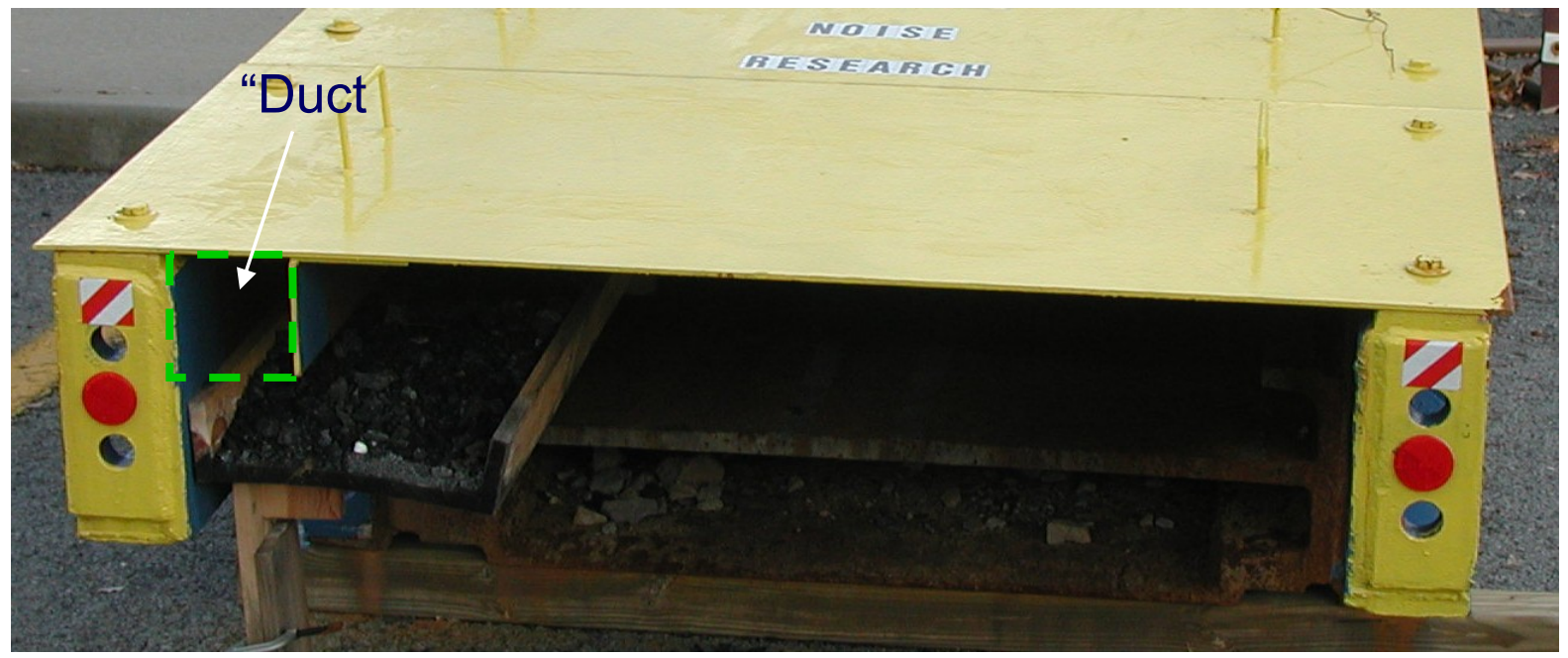

Figure 4.3 Tailpiece end of a stage loader 
To match the need of creating a standing wave within a duct, longwall stage loader proved to be the most promising candidate for ANC application (fig 4.3).

Fig. 4.4 is a snapshot of the equipments used in the ANC laboratory experiments. They are ( $L$ to $R$ ) EZ-ANC II and OROS (OR38) Analyzes. The experiments were performed on fourteen noise segments that were recorded inside an operating longwall stage loader with each of them being about 30 seconds long. The source noise was produced by a computer-driven speaker placed at one end of the duct. The input microphone was placed about $1.2 \mathrm{~m}$ away from the source speaker and connected to an EZ-ANC II controller. The ANC controller analyzes the source noise as well as the residual noise from the feedback error microphone. It then sends signals to the anti-noise speaker to generate the canceling noise into the duct system. The error microphone located near the exit of the duct also monitors the noise leaving the duct system for assessing the effectiveness of the noise reduction efforts.

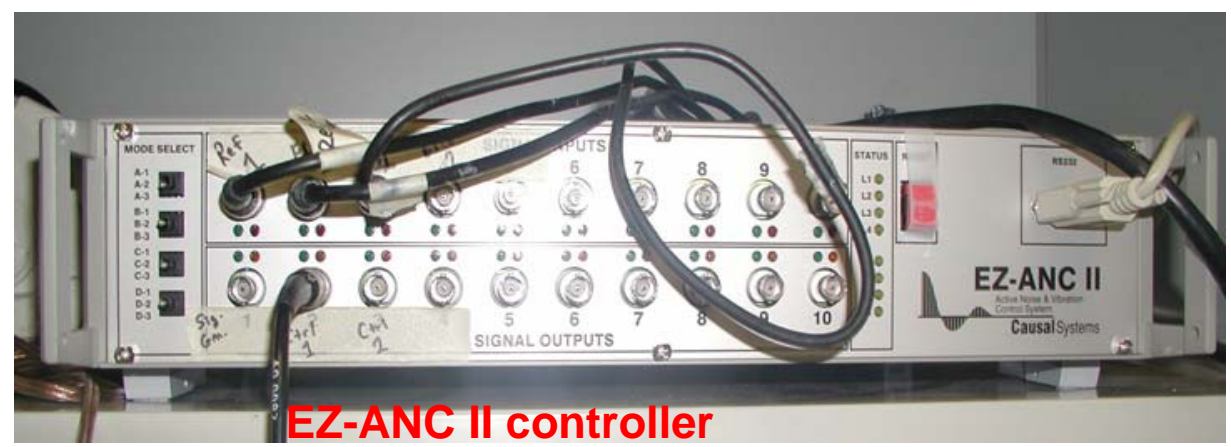

Analyze input signals, perform

FFT for producing anti-noise signals, analyze residual noise signal

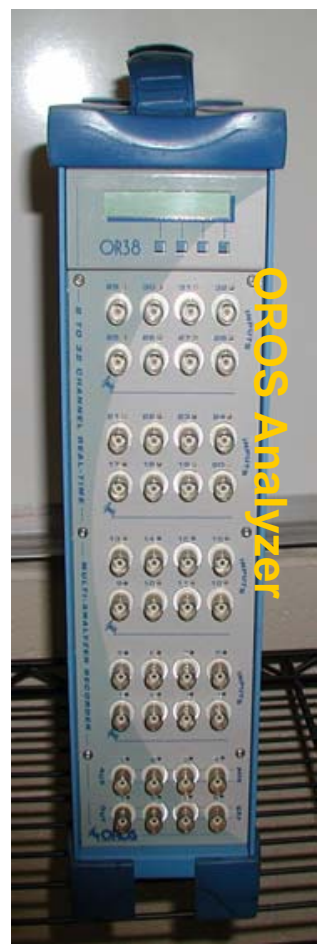

Figure 4.4 Equipments used in ANC laboratory experiments 
The EZ-ANC II controller is a semi-automatic system requiring manual inputs for many of the control parameters. The main objective of the laboratory studies is to find the set of control parameters that produce the best reduction effect for a given noise field. There are so many parameters to be controlled manually but only some important ones are cited in this paper. Extensive experiments were carried out on one of the recorded noise segments to find a desirable set of parameters. Then this set of control parameters were applied to the other recorded noise segments. Table 4.1 shows nine sets of tests performed on two noise segments (seven on segment $A$ and two on segment B) with two important control parameters listed.

The cancellation path transfer function checks the relation between control signal leaving the digital control filter and re-entering the control as an error signal. The base convergence coefficient (BCC) is one of the most important parameter in this function. It is basically a measure of how hard the adaptive control system should be forced to perform. The update rate in the cancellation path id is used to control the actual modeling rate. Another important control parameter, the base leakage value (BLV), is found to be the best at a fixed value of 0.001 for the experiments performed.

Fig. 4.5 shows a snapshot of manual input screen for EZ-ANC II controller. The variety of parameters can be adjusted as per need of the experiment. It is very important to get a balance and match the values with proper weightage needed by the control panel. 


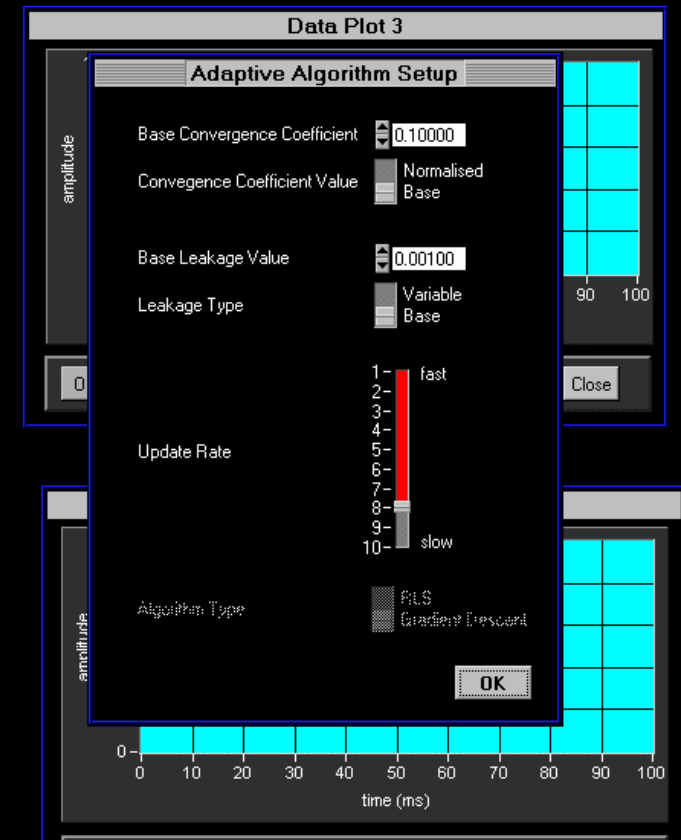

Off A- Error 1 Data Source Save Load Close

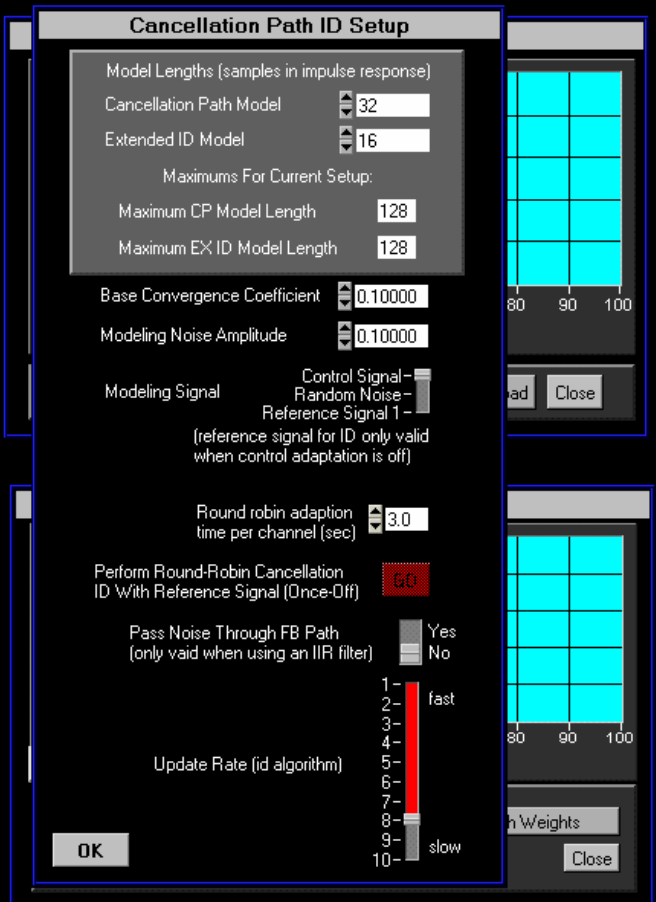

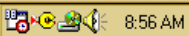

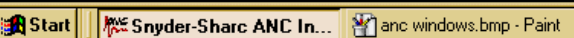

Figure 4.5 Manual Input screen for EZ-ANZ II controller 
For the nine sets of tests presented in this work, the base convergence coefficient ranges from 0.10 to 0.35 while the update rate ranges from 5 to 8 . For the two tests performed on noise segment $B$ (T15A and T16), the same parameters were used but the weights are (were) manually adjusted so that the sound volume of the anti-noise speaker can match with the source noise. Figure 4.6 presents the results screen capture of the OROS octave band analyzer.

Figure 4.7 shows the average sound levels measured with a sound level meter near the exit end of the duct system for noise segment $A$ with and without the ANC controller turned on. Without the ANC turned on (the original noise), the noise level varied from $97.2 \mathrm{~dB}$ to $100.3 \mathrm{~dB}$. For this segment, the sound level was higher in the first 12 seconds than that in the remaining duration. In the tests with the ANC turned on, the average sound level for test T15 ranged from 87.0 to $91.1 \mathrm{~dB}$ with an overall noise reduction of $9.6 \mathrm{~dB}$ as shown in Table 4.1. For test T17, the residual sound level was reduced to between 89.6 and $92.7 \mathrm{~dB}$ with the overall reduction being $7.7 \mathrm{~dB}$. 
Table 4.1 Testing parameters and noise reductions

\begin{tabular}{l|l|l|l|l|l|l}
\hline \hline \multirow{2}{*}{$\begin{array}{l}\text { Test } \\
\text { No. }\end{array}$} & \multirow{2}{*}{$\begin{array}{l}\text { Noise } \\
\text { Segment }\end{array}$} & BCC & \multirow{2}{*}{$\begin{array}{l}\text { Update } \\
\text { Rate }\end{array}$} & $\begin{array}{l}\text { Overall } \\
\text { Reduction } \\
\mathrm{dB}\end{array}$ & \multicolumn{2}{|l}{$\begin{array}{l}\text { Reduction at Sampling } \\
\text { Point }\end{array}$} \\
\cline { 6 - 7 } & & & $\mathrm{dB}$ & $\mathrm{dBA}$ \\
\hline 10 & $\mathrm{~A}$ & 0.01 & 5 & & 5.5 & -0.9 \\
\hline 11 & $\mathrm{~A}$ & 0.35 & 6 & & 5.5 & 1.0 \\
\hline 12 & $\mathrm{~A}$ & 0.25 & 6 & & 5.5 & 0.5 \\
\hline 13 & $\mathrm{~A}$ & 0.25 & 8 & & 6.0 & 1.0 \\
\hline 14 & $\mathrm{~A}$ & 0.20 & 8 & & 7.0 & 1.7 \\
\hline 15 & $\mathrm{~A}$ & 0.15 & 8 & 9.6 & 9.3 & 3.1 \\
\hline $15 \mathrm{~A}$ & $\mathrm{~B}$ & 0.15 & 8 & 7.3 & 7.3 & 2.8 \\
\hline 16 & $\mathrm{~B}$ & 0.15 & 8 & 9.3 & 7.9 & 2.7 \\
\hline 17 & $\mathrm{~A}$ & 0.10 & 6 & 7.7 & 7.9 & 1.9 \\
\hline \hline
\end{tabular}

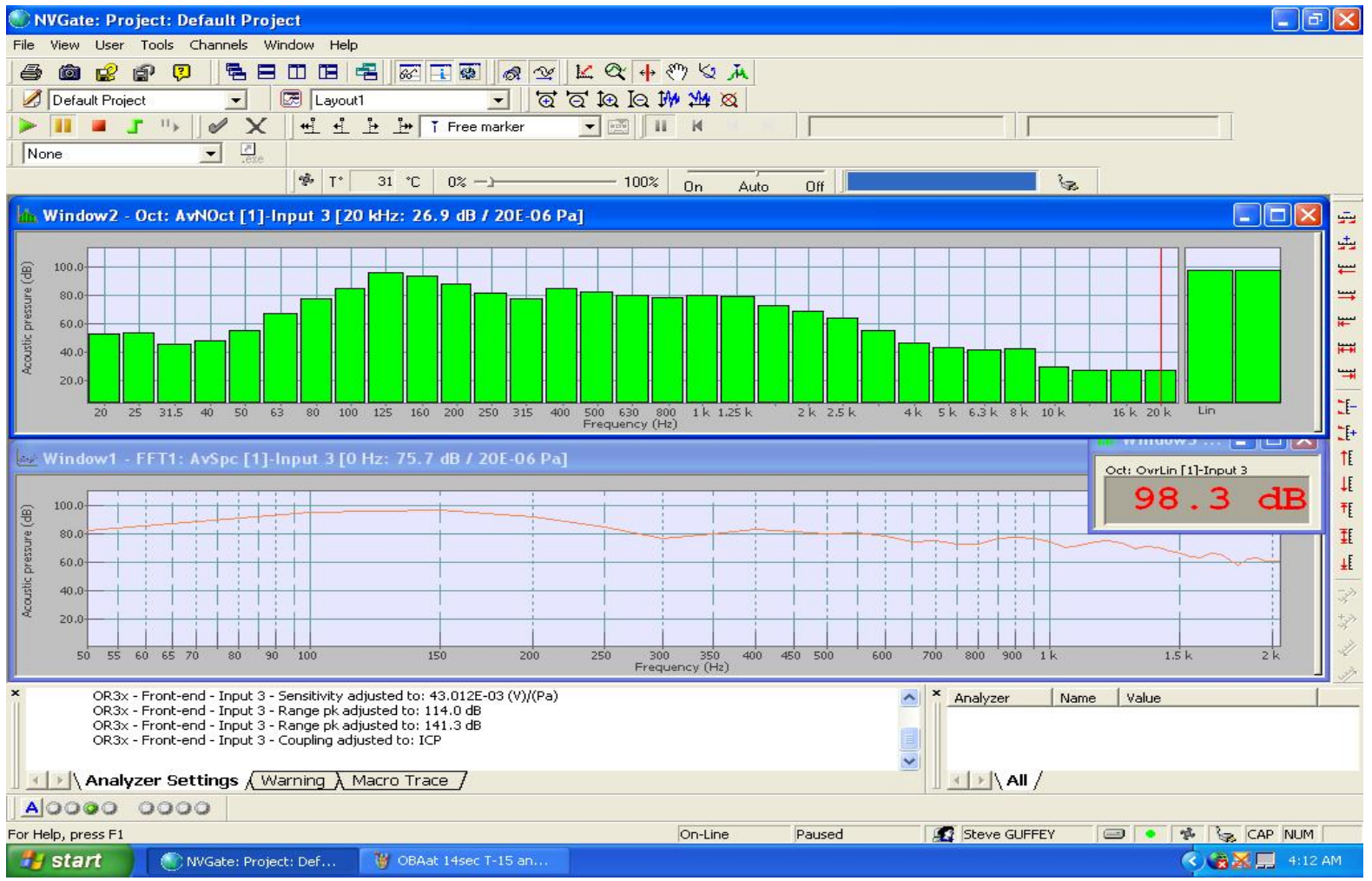

Figure 4.6 Result screen capture of the OROS octave band analyzer. 


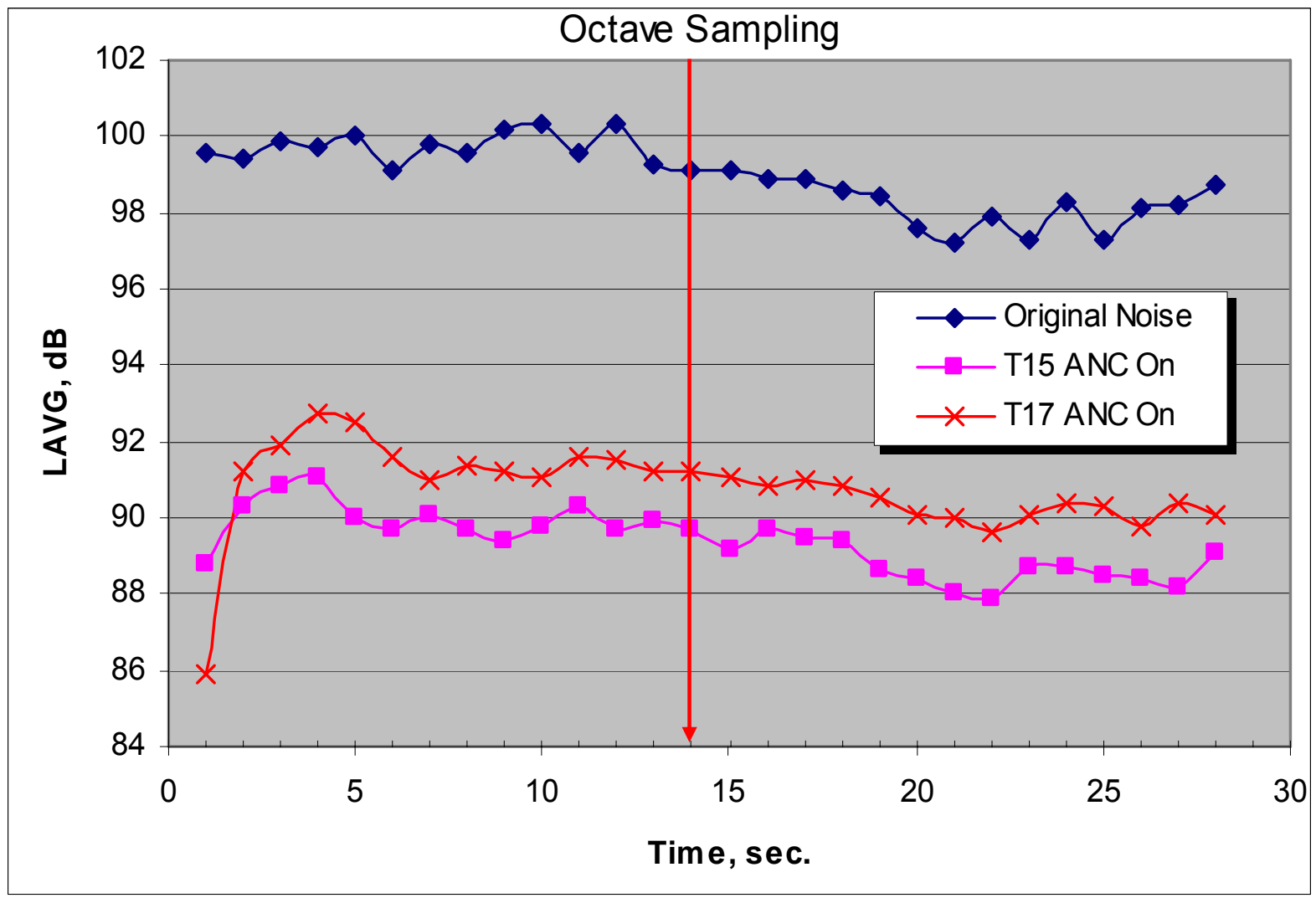

Figure 4.7 Measured on segment A of the recorded stage loader noise

The ANC controller has (had) also been set to attack the high noise level in the frequency range from $100 \mathrm{~Hz}$ to $650 \mathrm{~Hz}$. In order to show the effects, samples were taken, using the data acquisition system, from the noise segment $A$ at the time point $t=14 \mathrm{~s}$ for each of the tests. Octave band analyses were performed on the sampled data and the results are plotted in Fig. 4.8. For noise segment $A$, the peak sound pressure level before the ANC controller was turn on was in the frequency range from 100 to $250 \mathrm{~Hz}$. The tests with ANC turned 'on' show that all except test T10 were successful, at varying degrees, in reducing the noise level in the peak noise range. In test $\mathrm{T} 10$, due to its small base convergence coefficient $(\mathrm{BCC}=0.01)$ and slow update rate (5), the noise reduction in the peak range was not significant. The reduced sound pressure levels for the tests are plotted in Figure 4.9. It shows significant reductions were achieved in the frequency range from 80 to $250 \mathrm{~Hz}$ for all 
the tests except for test T10. For tests T14 and T15, the upper limit of the frequency range where significant reductions were observed was even extended to $630 \mathrm{~Hz}$. The largest noise reduction, $21.4 \mathrm{~dB}$, was achieved in test T15 at the frequency of $125 \mathrm{~Hz}$. In this test, the $\mathrm{BCC}$ and update rate were set at 0.15 and 8 , respectively. Figure 4.9 also show that for significant negative reductions, up to $-5.7 \mathrm{~dB}$, were observed in the frequency range from 1,250 to $3,150 \mathrm{~Hz}$ for tests T11 and T12 in which the $B C C$ were set at higher values ( 0.35 and 0.25 , respectively). The linearly average and the A-weighted noise reductions at the sampling point for all the tests are also listed in Table 4.1. The linearly average reductions on noise segment $A$ range from 5.5 to $9.3 \mathrm{~dB}$ with test T15 being the best. The A-weighted reduction for test T15 is a significant $3.1 \mathrm{dBA}$. Based on the tests performed, the control parameters of $B C C=0.15, B L V=0.001$ and the update rate at 8 appeared to achieve the best noise reduction on noise segment $A$.

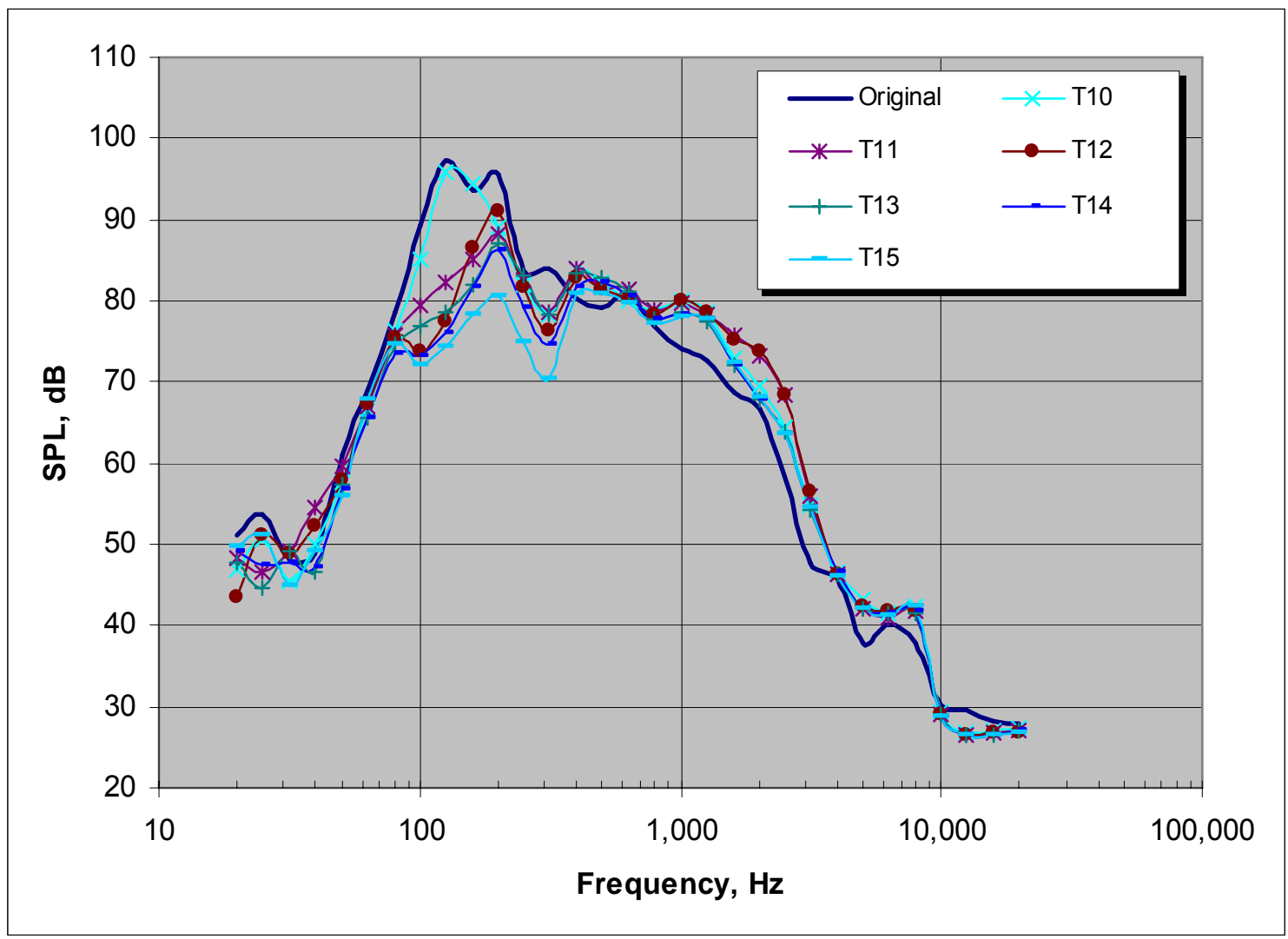

Figure 4.8 Measured sound pressure levels vs. frequency for various tests on noise segment $A$ 
Tests were also performed to resolve the undesirable negative reduction problem in the higher frequency range $(1,250$ to $3,150 \mathrm{~Hz})$ in tests T11 and T12 (Fig. 4.9) by targeting the ANC algorithm in that frequency. These tests were performed with the same basic control parameters as before but with selected higher frequency range. The tests achieved reductions between zero and $0.8 \mathrm{~dB}$ in the high frequency range from $1 \mathrm{kHz}$ to $20 \mathrm{kHz}$. Although the reductions are not significant, they eliminated the negative reduction problems in the previous two tests. On the other hand, these tests show that to use ANC technology to reduce high frequency noise is indeed ineffective.

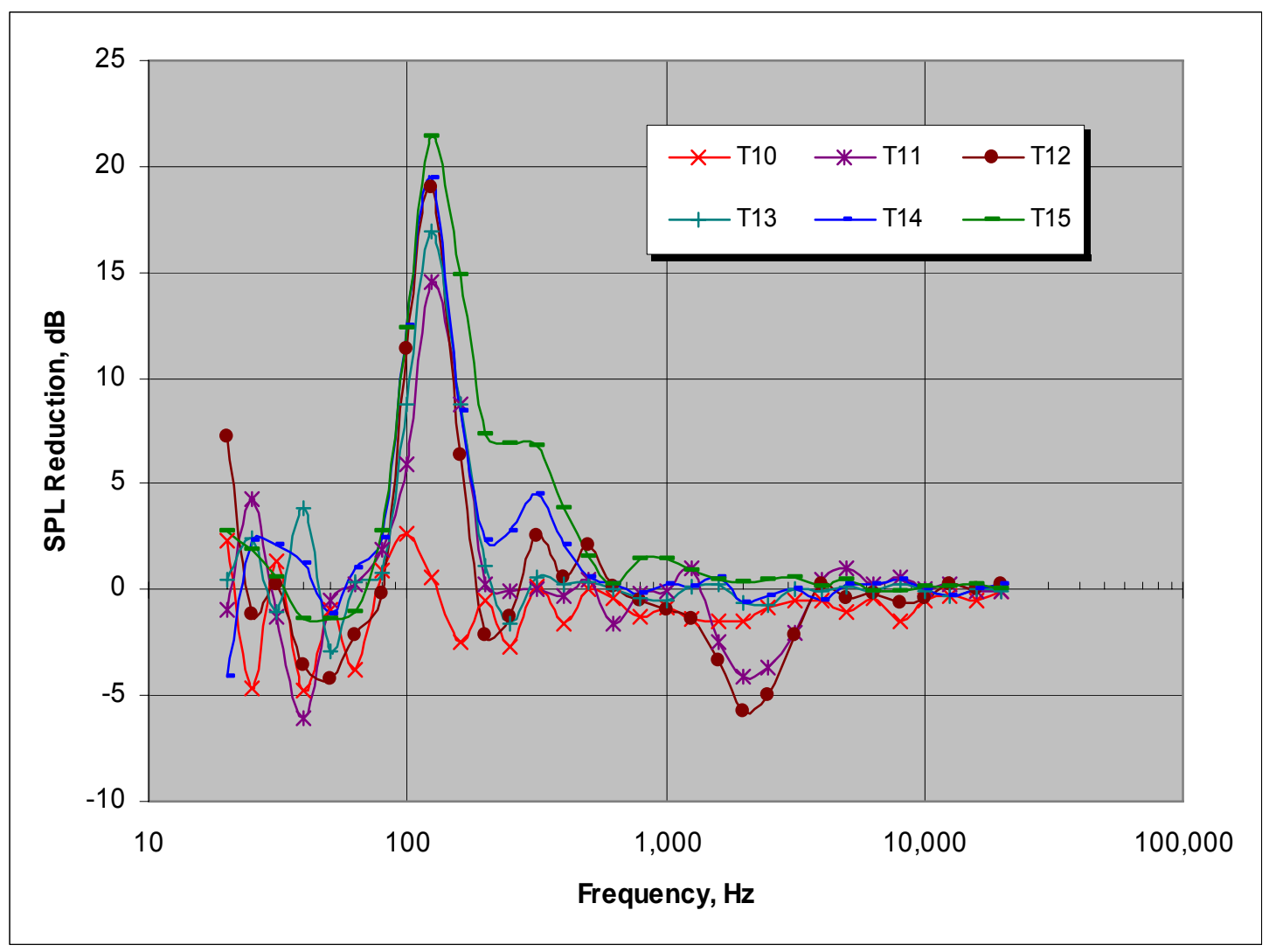

Figure 4.9 Reductions on sound pressure levels at different frequency sampled at $t=14$ seconds on noise segment $A$ 
In order to check the applicability of the best set of control parameters previously determined (the ones used in test T15) to the other noise segments, they were used in two tests (T15A and T16) performed on noise segment B. Between these two tests, the weights that control the anti-noise speaker volume are also varied. The measured average SPL before and after application ANC algorithms is plotted against the time in Fig. 4.10. The overall reductions for the 28-second long noise segment are 7.3 and 9.3 for tests T15A and T16, respectively.

Octave band samplings were also performed at the time point $\mathrm{t}=14 \mathrm{~s}$ in test T16. The SPL-frequency distributions at the sampling point before and after ANC is applied as well as the noise reductions are shown in Fig. 4.10 Again, the most significant noise reduction was achieved in the frequency range from 90 to $630 \mathrm{~Hz}$ with the maximum reduction of $25 \mathrm{~dB}$ at the frequency of $125 \mathrm{~Hz}$. The linearly and A-weighted average noise reductions for test $\mathrm{T} 16$ are $7.9 \mathrm{~dB}$ and $2.7 \mathrm{dBA}$, respectively.

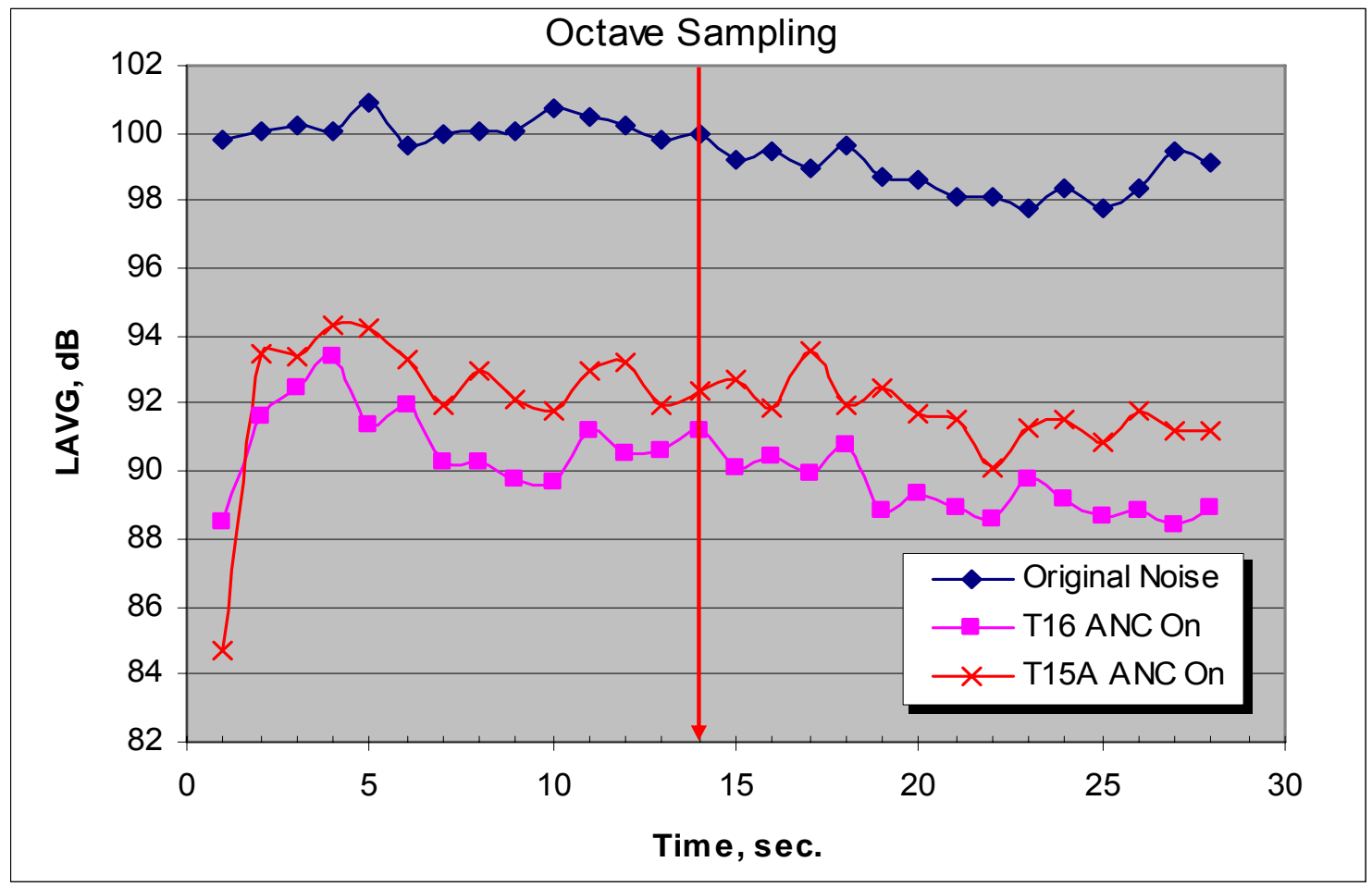

Figure 4.10 Reductions on segment B of the recorded stage loader noise 


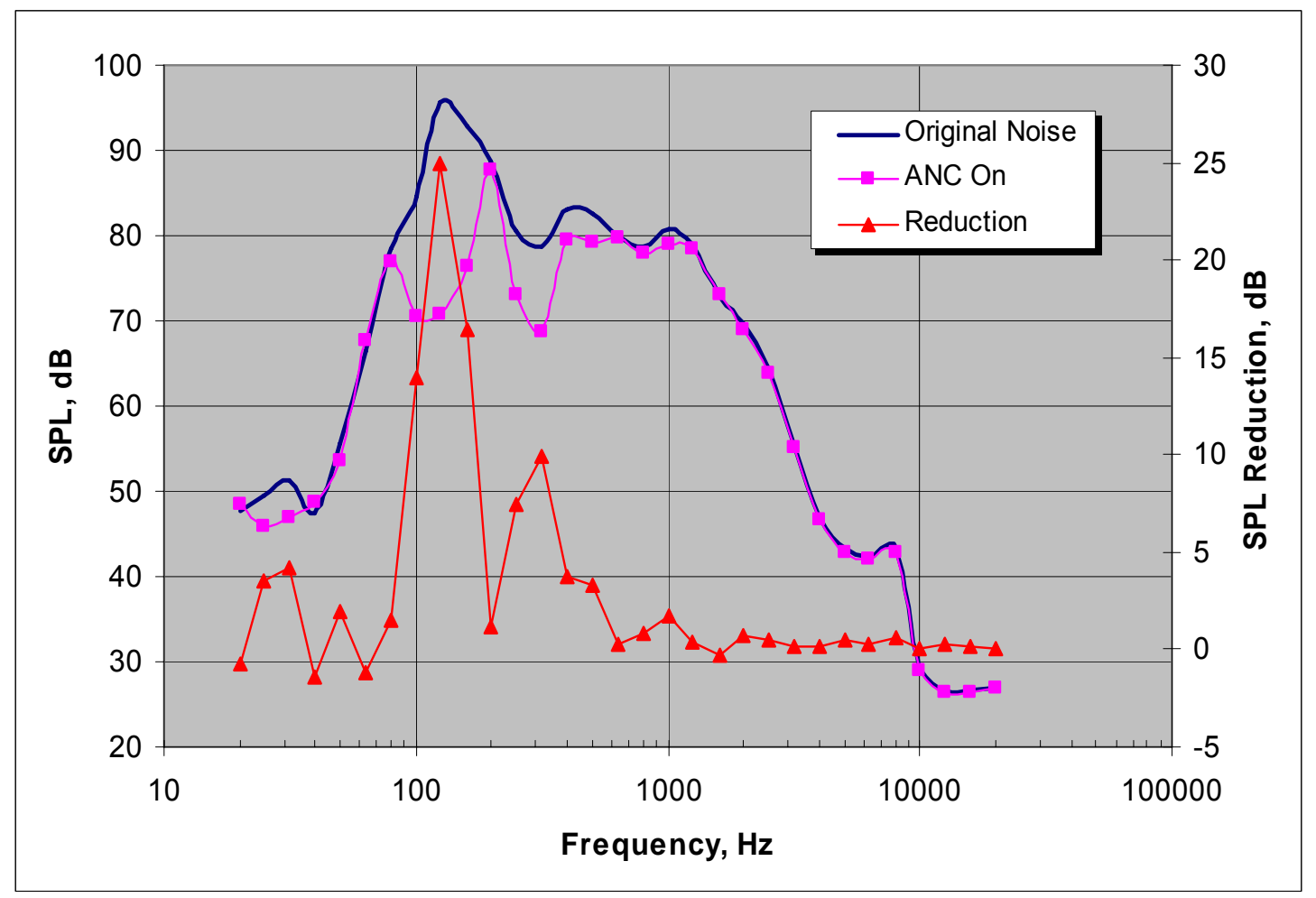

Figure 4.11 Measured sound pressure levels and reduction for test T16 on noise segment B. 
One additional test has also been conducted when all the 14 recorded noise segments are joined together. The control parameters that have been used in test T15 are implemented in this test. The results before and after the ANC algorithm is applied are shown in Fig. 4.12. It shows that ANC is capable of reducing the noise level for every noise segment and the overall reduction in the 433-second duration is $5.7 \mathrm{~dB}$.

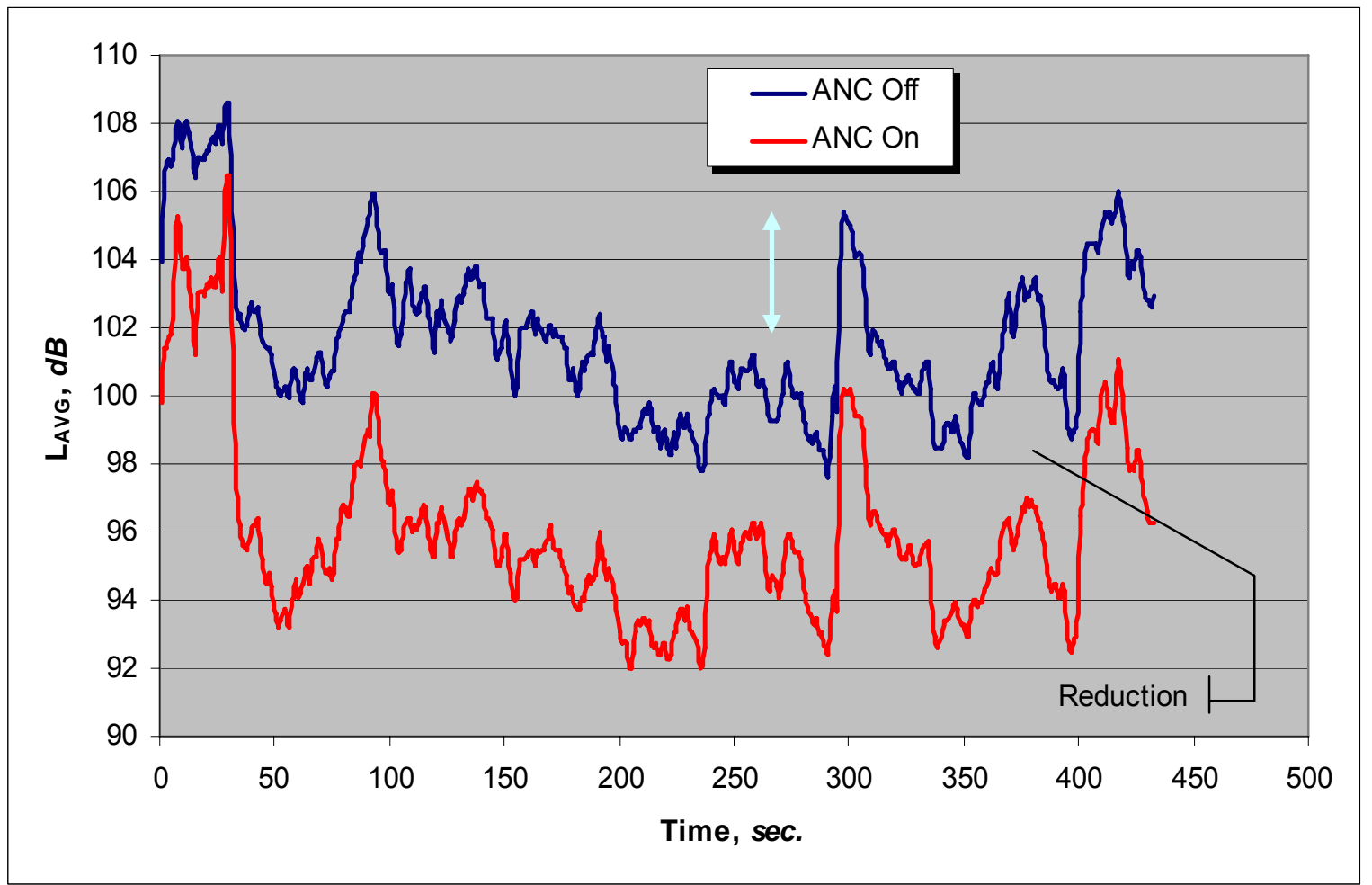

Figure 4.12 Tests performed on all 14 noise segments with the control parameters used in test T15. 


\section{RESULTS AND DISCUSSIONS}

\subsection{RESULTS:}

The noise monitoring on the stageloader section has illustrated the presence of high Leq which creates potential harmful noise exposure work environment. The study revealed the scarcity of previous database for noise surveys. The crosssectional survey of mining noise sources explains the contribution of low frequency dominance to the overall sound pressure level. The recorded noise levels around the face equipments ranged from 88 to $104 \mathrm{dBA}$.

For the nine sets of tests presented in this work (Table 4.1), Without the ANC turned on (the original noise), the noise level varied from $97.2 \mathrm{~dB}$ to $100.3 \mathrm{~dB}$. In the tests with the ANC turned on, the average sound level for test T15 ranged from 87.0 to $91.1 \mathrm{~dB}$ with an overall noise reduction of $9.6 \mathrm{~dB}$ as shown in Table 5.1. For test T17, the residual sound level was reduced to between 89.6 and $92.7 \mathrm{~dB}$ with the overall reduction being $7.7 \mathrm{~dB}$. Also the average sound levels measured with a sound level meter for noise segment $A$ with and without the ANC controller turned "ON", the sound level was higher in the first 12 seconds than that in the remaining duration.

The most significant noise reduction was achieved in the frequency range from 90 to $630 \mathrm{~Hz}$ with the maximum reduction of $25 \mathrm{~dB}$ at the frequency of $125 \mathrm{~Hz}$. The linearly and A-weighted average noise reductions for test T16 are $7.9 \mathrm{~dB}$ and $2.7 \mathrm{dBA}$, respectively. 


\subsection{DISCUSSIONS}

The hearing loss can be prevented by controlling the noise at the source or utilizing personal protective equipment and is measurable with audiometric tests. The engineering control e.g. ANC is a method to control the noise by canceling the unwanted sound.

For the Laboratory set-up and the other parameters considered in this work, the following are the significant observations with regard to the influence of the low frequencies on overall SPL and effectiveness of ANC technology with stability and reliability:

- In general, the most of the machinery used in longwall face showed similar frequency spectrum i.e. high dominant low frequencies. However, depending on the available processors and the present technology maximum use of ANC technology is very limited.

- The stageloader section had high Leq which is a potential harmful noise. In such a condition proper selection of hearing conservation program (HCP) plays a vital role. The key elements for the HCP could be

$>$ Noise Exposure measurement

$>$ Engineering and administrative noise exposure controls

- ANC can work much better for the lower frequencies up to $800 \mathrm{HZ}$. Again, depending on the set-up conditions discussed in the previous sections, minimum and maximum cancellation results may be seen up to $1000 \mathrm{~Hz}$.

- When the ANC is applied, the cancellation effects depend on the characteristics of sound fields such as the maximum SPL, dominant frequencies and the location of the noise source, etc.

- Also, these results found for the random noise direct a new direction of a possible engineering control through ANC technology in the mining industry. 


\section{CHAPTER}

\section{CONCLUSIONS}

The reliability of an engineering noise control depends on many factors and methods available, the ANC technology is one among them. There are some good works available in the published literature as discussed in chapter 2, also other industries have successfully applied ANC technology. This thesis is an endeavor made to explore the solid chance of adapting ANC technology in the mining industry. The results of this research have been summarized below. Considering the limited nature of this thesis, still many parameters are yet to be explored. A suggestion for the possible areas for future research is also envisaged and recommendations for possible design consideration are included.

The following conclusions can be drawn from this noise research:

- Field noise surveys have been conducted to characterize the noise field in and around the longwall faces in three underground coal mines in northern Appalachian coalfields. It is found that the crusher/stage loader assemblies are usually one of the noisiest machines in a most congested area in these longwall faces. The octave band analysis showed lower frequencies $(100 \mathrm{~Hz}$ $-650 \mathrm{~Hz}$ ) as dominant frequencies in contributing to overall noise level.

- The crusher/stage loader is selected for ANC application. Several laboratory experiments have been conducted on the noise segments recorded from longwall stage loaders. The experiments have shown that the ANC can achieve significant noise reductions if proper control parameters have been used. The frequency range within which the noise reductions are significant is from $100 \mathrm{~Hz}$ to $650 \mathrm{~Hz}$ - consistent with the dominant frequency range of surveyed longwall noise sources. The overall noise reductions are in the range from $5.5 \mathrm{~dB}$ to $9.3 \mathrm{~dB}$. 
- However, the ANC was not very effective in reducing the portion of the noise in frequency higher than $1,000 \mathrm{~Hz}$ at the current stage of our research. A combined approach using both the active and passive noise (more effective for high frequency noise) controls would be preferred. For example, by adding mass, enclosure and vibration dampening to the crusher/stage loader can reduce the noise level where the controls are added. Then the ANC could be used to reduce the noise that is channeled down the stage loader. 


\begin{tabular}{|c|l|}
\hline CHAPTER & \\
\cline { 1 - 1 } & \multirow{2}{*}{ FUTURE RESEARCH } \\
\hline
\end{tabular}

Noise source and noise exposure both can be controlled. To apply the understanding of ANC technology and its effectiveness in the mining industry, the following factors are still need to be considered for developing a reliable noise control technology:

- Understand the low frequency spectrum for all machines used in the underground mining industry.

- Understand the effect of confinement, temperature and dust, etc on noise pattern of the section or area of work.

- In mining industry, very limited noise recording instruments are available due to intrinsic safety issues. There is a need for more advanced digital real time noise recording instrument.

Recommendations for design considerations and noise control:

- Recognize the desirability of controlling the existing noise level and then thorough study for the feasibility of noise controls to be applied.

- Machine vibration is major source of noise. To cut down on vibration, a planned size of stage loader should be selected, if the geo-mining conditions permit. Longer the better, as the mass of stage loader increases and vibration is reduced.

- Hearing conservation program should adopted, with the key elements:

$>$ Noise exposure measurement

$>$ Engineering and administrative noise exposure control

$>$ Personal hearing protection

$>$ Audiometric testing and follow-up, and 
$>$ Education

- Good database of machine noise surveys should be maintained and an optimum relation can be drawn for maintenance requirement based on the noise source of the different parts. Also, replacement of machines can be designed after certain number of maintenance cycle. 


\section{REFERENCES}

Armour, D., 2003 "New Dosimeter Readings Reveal Better Noise Dosage Data", Coal Age / VOL. 108, NO.8, pp 30-37.

Bartholomae, R. C., and Burks, A. J., 1996 "Longwall Mine Noise and Recommendations to Reduce Worker Noise Exposure", Noise-Congress 96, Seattle, Washington, 1996.

Bartholomae, R.C., 1983 "Mining Machinery Noise Control Guidelines", UBBM.

Bauer, E.R., and Babich, D. R., 2004 "Administrative Controls for Reducing Workers Noise Exposure", 049, SME.

Berger, E. H., L. H. Royster., J. D. Royster., D.P.Driscoll., and M.Layne."The Noise Manual", $5^{\text {th }}$ Edition.

Bies, D. A., and Hansen, C. H., 2003, "Engineering Noise Control", $3^{\text {rd }}$ Edition, Newyork, NY, pp 35 to 75

Chiang, H. S., Luo, Y. and Peng, S. S., 1987 "Airborne Dust Distribution in Longwall Faces", International Journal of Mining and Geological Engineer, Vol.5 pp. 433-440.

International Standard ISO 1999.2, 1990, "Acoustics-determination of Occupational Noise exposure and estimation of Noise induced hearing impairment", Geneva Switzerland.

McKinney, R., 2004, "Program Information Bulletin No. P16," U.S. DOL, MSHA, 2004.

Mine Safety and Health Administration, Health Standards for Occupational Noise Exposure; Final Rule 30 CFR Parts 56, 57, 62, 70 and 71; 64 Federal Register pp. 49548-49634.

MSHA, 2001, Coal Mine Health Inspection Procedures Handbook (PH89-V1(13)), Mine Safety and Health Administration, Arlington, VA.

Nienhaus, K., Lange, U., and Bayer, A. K., "Big Is Not Always Beautiful", American Longwall Magazine, May 2005 pp 21-23.

Peng, S. S., H. S. Chiang., 1984 “Longwall Mining”, Wiley and Sons, pp 28-39. 
Peterson, J. S., Kovalchik, P. G., Matetic, R.J., 2005 "A Sound Power Level of a Roof Bolter." Pre-print 05-72. Annual SME meeting, Salt Lake City, Utah.

Rai, A. R., Luo, Yi., and Peng, S. S., 2005 "Experimental Studies of Applying Active Noise Cancellation Technology to Reduce Stage Loader noises", Preprint 05-124, Annual SME meeting, Salt Lake City, Utah.

Snyder, S. D., Hansen, C. H., and Vokalek, G., 1999 "EZ-ANC II", Guide Casual Systems, Australia.

Valoski, M. P., 1993, "Evaluation of the Applicability of Noise Cancellation Technology to Mining", U.S.DOL, Pittsburg Safety and Health Technology Center, Physical and Toxic Division, Pittsburg.

Valoski, M. P., 1997, "Noise Induced Hearing Loss among Coal Mining Occupations", Noise Congress 1997. 


\section{BIODATA}

The Author was born on December 08, 1979 in Lonavla, near Mumbai (Bombay), India. He did his Bachelors in Mining Engineering (May 2003) from Visvesvaraya National Institute of Technology (formerly REC-Nagpur), India. His Bachelors project was on "Study of Accidents due to Inundation in India".

$\mathrm{He}$ joined West Virginia University in Fall 2003 for Master of Science in Mining at the Department of Mining Engineering, WVU. He worked as a Graduate Research Assistant from Fall 2003 to August 2005 for his academic advisors Dr. Yi Luo and Dr.Syd Peng during his M.S.

He worked as a summer intern for MEPCO Engineering in 2005. Presently he is employed fulltime Mining engineer with Foundation Coal Company. 